\title{
Studies on the Internal Ballistics of Composite Solid Rocket Propellants Incorporating Nano-Structured Catalysts
}

\author{
Mukesh R. ${ }^{1}$, Sivasubramaniyam R. ${ }^{2}$, Elangovan R. R. ${ }^{1}$, Abhinaya Sree R. ${ }^{1}$, Harish R. ${ }^{1}$, \\ Rajashree D. ${ }^{1}$, Satish Kumar Kanhar ${ }^{1}$ \\ ${ }^{1}$ Department of Aeronautical Engineering, A.C.S College of Engineering, Bangalore, India \\ ${ }^{2}$ Department of Mechanical Engineering, A.C.S College of Engineering, Bangalore, India \\ Email: vsmprm@gmail.com
}

How to cite this paper: Mukesh R., Sivasubramaniyam R., Elangovan R.R., Abhinaya Sree R., Harish R., Rajashree D., Kanhar, S.K. (2017) Studies on the Internal Ballistics of Composite Solid Rocket Propellants Incorporating Nano-Structured Catalysts. Advances in Aerospace Science and Technology, 2, 48-72.

https://doi.org/10.4236/aast.2017.24005

Received: September 8, 2017

Accepted: December 16, 2017

Published: December 19, 2017

Copyright $\odot 2017$ by authors and Scientific Research Publishing Inc. This work is licensed under the Creative Commons Attribution International License (CC BY 4.0).

http://creativecommons.org/licenses/by/4.0/

\begin{abstract}
This paper deals with the analysis of burn rate using various catalysts of Iron Oxide and determining which gives the higher burn rate with low pressure variation. The Ammonium Perchlorate (AP) was obtained and ground into fine powder with the particle size ranging from 63 to $125 \mu \mathrm{m}$. The propellant strands were prepared with proportions by mixing AP with the binder (Hydroxyl Terminated Polybutadiene), the catalyst (Iron Oxide), curing agent (Isophorone diisocyanate) and the plasticizer (Dioctyladipate). The prepared propellant mixture was cured at around $63 \mathrm{deg} \mathrm{C}$ to get various propellant strands. The first strand was prepared with the absence of a catalyst to set an initial base of comparison with other Iron Oxide catalysts, namely, Flower Shaped, Micro and Nano, based on the size of the particles. The combustion process was carried out in a strand burner, which was in turn connected to a data acquisition system. The obtained output was analysed in the form of graphs. The burn rate was achieved by calculating the slope of the graph i.e. by calculating the difference between the highest and the lowest peak of the graph and dividing the total time by the answer. The experiment was repeated with the different catalyst types, as mentioned above, at different pressures. It was observed that the Nano shaped Iron Oxide exhibits better burning characteristics when compared to the rest with the pressure index of 0.792 . In this paper, the various experiments carried out along with their procedures are explained in detail. The results obtained and the techniques used are also elaborately described in this paper.
\end{abstract}

\section{Keywords}

Ammonium Perchlorate, Dioctyladipate, Hydroxyl Terminated 
Polybutadiene, Isophorone Diisocyanate

\section{Introduction}

Ammonium Perchlorate (AP) is widely used as an oxidizer in composite solid propellants. The ballistics of a composite propellant can be improved by adding a catalyst such as Ferric Oxide $\left(\mathrm{Fe}_{2} \mathrm{O}_{3}\right)$, Copper Oxide $(\mathrm{CuO})$, Copper Chromite $\left(\mathrm{CuO} . \mathrm{Cr}_{2} \mathrm{O}_{3}\right)$, Nickel Oxide (NiO), etc., which accelerates the rate of decomposition of AP. The primary use of Ammonium Perchlorate, $\mathrm{NH}_{4} \mathrm{CLO}_{4}$, is as an oxidant in solid propellants. The particle size of AP plays a very important role in dictating the burning behaviour of the composite propellant. Thus AP is to be fine powdered. Recent investigations have shown us that nanoparticles of transition metal oxides, without any agglomeration can increase the burning rate effectively. The efficiency of catalytic action increases sharply in Nano size oxide particles than micro scale oxide particles. Ammonium Perchlorate contains 34\% available oxygen, considerably less than that of the Sodium or Potassium salts [1].

Binders determine the mechanical properties of the propellant. Hydroxyl Terminated Polybutadiene (HTPB) is a long chained clear liquid rubber polymer. Binders provide structurally a matrix in which solid granular ingredients are held together in a composite propellant. Nearly $10 \%$ to $15 \%$ of the composite solid propellant is comprised of binders. The curatives react with the functional groups of the binder and forms cross linked polymeric network structure. The number of cross-links in the network decides the mechanical behaviour of the polymer [1].

A curing agent causes the pre-polymers to form longer chains of larger molecular mass and interlocks between chains. HTPB is cured by isocyanates. Some require an elevated temperature (oven cure) of $125^{\circ}+\mathrm{F}$ to activate, while others such as Isophorone diisocyanate (IPDI) or PAPI; are active at room temperature. The process ability of the highly solid filled propellant slurry is made easy by employing plasticizers which are compatible with all ingredients. Plasticizers are high boiling, non-volatile, low molecular weight substances. Here the plasticizer used is Dioctyladipate (DOA). It is a relatively low-viscosity organic liquid, which also contributes to the thermal energy on oxidation. This colorless liquid has low acute oral toxicity, but is considered as a high health hazard due to its mutagenic and carcinogenic effects [1]. The ingredients used are shown in the Figure 1.

Various burn rate enhancers have been used to obtain the burn rate. In order to achieve a higher burning behavior catalysts are used. Catalyst can be defined as the substance that increase or decrease the rate of a chemical reaction without itself undergoing any permanent chemical change. With a catalyst, reactions occur faster and require less activation energy. The current work involves Iron 


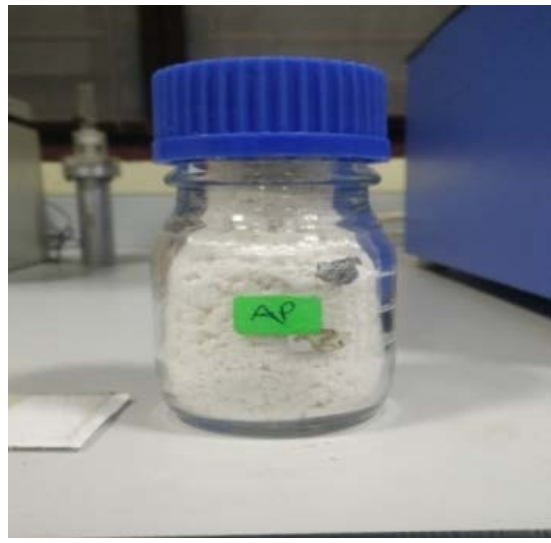

(a)

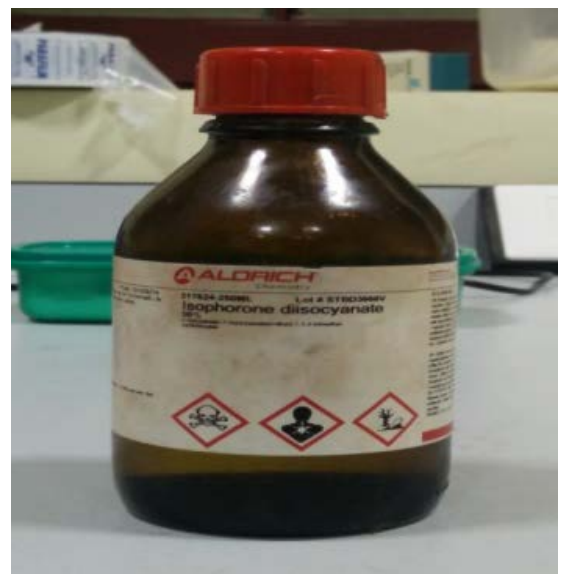

(c)

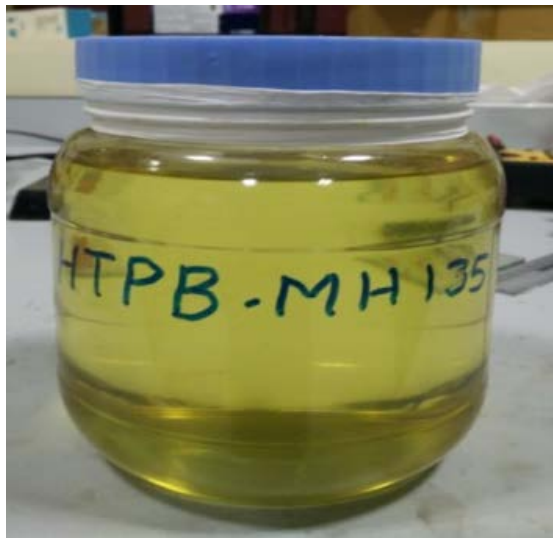

(b)

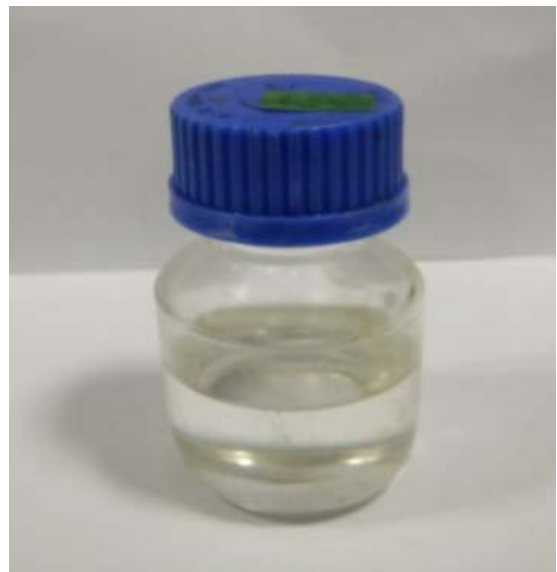

(d)

Figure 1. (a) Ammonium Perchlorate; (b) Hydroxyl Terminated Polybutadiene (HTPB); (c) Isophorone diisocyanate; (d) Dioctyladipate (DOA).

oxide as the catalysts. Iron Oxides are chemical compounds composed of Iron and Oxygen. Altogether, there are sixteen known Iron Oxides and Oxy-Hydroxides. Iron (III) Oxide is one of the three main Oxides of Iron, the other two being Iron (II) Oxide, which is rare, and Iron (II \& III) Oxide, which also occurs naturally as the mineral Magnetite as the mineral known as Hematite, is the main source for steel industry. Iron (III) Oxide is ferromagnetic, dark red, and readily attacked by acids, often called as Rust, and to some extent this label is useful, because rust shares several properties and has a similar composition. The different type of Iron Oxide used in this experiment are:

a. Flower shaped Iron Oxide

b. Micro shaped Iron Oxide

c. Nano shaped Iron Oxide

The catalysts mentioned above were named with respect to their shape and size as observed under a microscope.

The various forms of Iron Oxide are shown in the Figure 2.

We are mainly focusing on the effect of the catalyst. The catalyst is $2 \%$ of AP. The small percent of catalyst greatly improves the burn rate. 


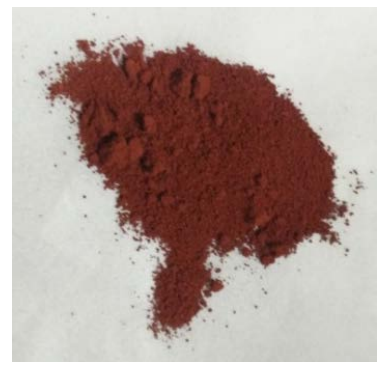

(a)

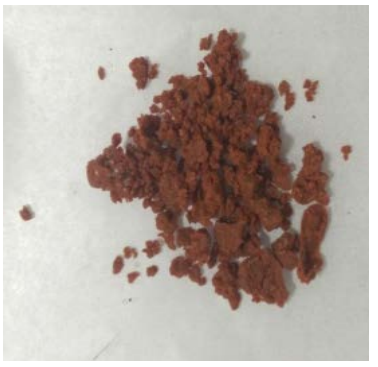

(b)

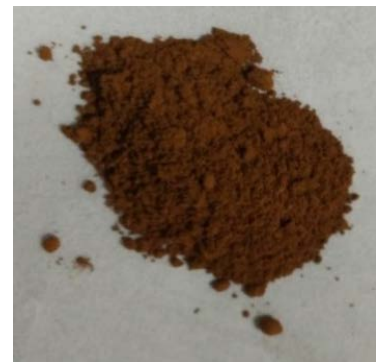

(b)

Figure 2. (a) Iron Oxide (micro particles); (b) Iron Oxide (nano particle); (c) Iron Oxide (flower shaped).

Dry Mixing-The AP and catalyst is mixed in a dry mixer. The apparatus used for dry mixing is a V-blender. This is mainly used to get a uniform mixture of the oxidizer. The operation is carried out for about twenty minutes. Ammonium Perchlorate and catalyst (Iron Oxide) is mixed well in the dry mixer to get a uniform mixture. The maximum speed of the instrument used is $100 \mathrm{rpm}$.

Wet Mixing-The oxidizer along with the fuel, plasticizer and curing agent is kept in the wet mixing. The operation is carried around for thirty minutes. The mixture is heated in wet mixing until a slurry propellant is formed. Then it is taken out and injected into a straw.

\subsection{Burn Rate}

The burning surface of a rocket propellant grain recedes in a direction perpendicular to this burning surface. The rate of regression, typically measured in inches per second (or mm per second), is termed burning rate (or burn rate).

This rate can differ significantly for different propellants, or for one particular propellant, depending on various operating conditions as well as formulation. Knowing quantitatively the burning rate of a propellant, and how it changes under various conditions, is of fundamental importance in the successful design of a solid rocket motor [2] [3] [4] [5] [6].

Burn rate is profoundly affected by chamber pressure. The usual representation of the pressure dependence on burn rate is the Saint Robert's Law:

$$
\mathrm{r}=\mathrm{ro}+\mathrm{aPc}^{\mathrm{n}}
$$

where, $r$ is the burn rate,

$r o$ is a constant (usually taken as zero),

$a$ is the burn rate coefficient,

$n$ is the pressure exponent.

\subsection{Strand Burner}

The Strand Burner (sometimes referred to as the Crawford Strand Burner) is an apparatus that provides for burn rate measurements of a solid rocket propellant in an environment of elevated pressure. The propellant sample being tested, referred to as a strand, is burned within the confines of a pressure tank, called a 
Firing Vessel. The strand is in the form of a pencil-like stick, and it is electrically ignited at one end. The time duration for the strand to burn along its length (cigarette fashion) is measured. Various means are used to measure the time duration, such as lead wires embedded in the strand which melt when contacted by the flame front, or by use of thermocouples. This strand burner is connected to a cylinder containing nitrogen gas [2]. The maximum pressure capacity is 120 bars. There is an outlet pipe which is connected to the strand burner, after the combustion the pressure is released through it. The burn rate data is obtained by connecting it to a data acquisition system. There are various techniques to determine the burn rate. We use the fuse wire method to determine the burn rate.

\section{Fuse Wire Method}

The cured propellant strand is connected with conducting fuse wires at a distance of $10 \mathrm{~mm}$ apart, along the length. The resultant strand is placed in the strand burner which are in turn connected to the data acquisition system and sealed inside the chamber where the combustion of the propellant takes place.

After the setup is sealed, nitrogen gas of required pressure is passed and checked for leakage. The data acquisition system, connected to the setup, is checked for connectivity and the process is started to get the output in the system. The process is continued for various pressures and various catalysts. Graphs are plotted and burn rate is calculated.

By investigations, we conclude that various researches have been conducted to analyze the burn rate. Different techniques have been carried out to get the required results. The burn rate enhancers used in different papers yield to many different properties. Ammonium perchlorate (AP) is the most commonly used oxidizer in composite solid propellants. The purpose of this paper is to scientifically investigate the catalytic mechanism of thermal decomposition (burn rate) of AP. An experiment was conducted to study and hence analyze the various catalysts of Iron Oxide and conclude which contributes to an improved burn rate. Our paper mainly focuses on using the various forms of Iron Oxide as catalysts to enhance the burn rate. The AP particles were mixed with HTPB, IPDC, DOA and the catalysts to obtain propellant strands and the combustion process was carried out to obtain the output which was analysed in the form of graphs. The burn rate was achieved by calculating the slope of the graph. The experiment was repeated with the different catalyst types at different pressures. Our paper provides a basic insight on the studies of the internal ballistics (thermal decomposition) of Ammonium Perchlorate using different catalysts of Iron Oxide which benefits us to understand which offers high energetic efficiency at less consumed time.

\section{Experimental Analysis}

\section{Re-Crystallisation of AP}

Ammonium Perchlorate (AP) was obtained by re-crystallisingit twice to obtain 
pure white sample. First, the solute was dissolved in the solvent-boiling solvent was added to a beaker containing the impure compound. The beaker was heated and the solvent was added continuously till the solute was completely dissolved. After the dissolution, the crystals of the solute were obtained-the pure crystals of the solute are the desirable part of the mixture, and so they must be removed from the solvent. Filter paper was used in the funnel to remove unwanted impurities. Then it was allowed to cool down at room temperature and kept for a day. The same process was repeated to obtain a much purer form of AP. The slower the rate of cooling, the larger the crystals are formed. The AP thus obtained was grounded to a fine powder. In our experiment, the size of AP particles range from $63-125 \mu \mathrm{m}$. This was obtained using the electromagnetic sieve shaker [7] [8] [9].

The three propellant slurries were prepared with $78.4 \%$ solid loading. For the three catalysed samples the catalyst content was kept at $2 \mathrm{wt} \%$ (w.r.t AP).The propellant test samples were prepared by allowing the propellant to cure in polypropylene drinking straws with internal diameter of $5.5 \mathrm{~mm}$. The samples were cured at a temperature of $63^{\circ} \mathrm{C}$ for one week. The propellant slurry with the absence of a catalyst was also prepared to set an initial base of comparison for the rest of the catalyst based propellant using the same procedure as mentioned above. The propellant prepared is in the ratio as shown in the Table 1.

The propellants prepared are elucidated below:

\section{Without Catalyst.}

Total $=15 \mathrm{~g}$

Step 1: Ammonium Perchlorate was taken and weighed.

$\mathrm{AP}=12 \mathrm{~g}(80 \%$ of total $)$

Step 2: HTPB was added to the weighed AP. Then, to this mixture plasticizer (DOA) and curing agent (IPDC) were added.

$$
\begin{aligned}
& \text { HTPB }=3 \mathrm{~g}(20 \% \text { of total }) \\
& \text { DOA }=0.16 \mathrm{~g}(5 \%-8 \% \text { of HTPB }) \\
& \text { IPDC }=0.19 \mathrm{~g}(5 \%-8 \% \text { of HTPB })
\end{aligned}
$$

Step 3: The above mixture was then mixed by the process of wet mixing. It is then injected into straws of length $4 \mathrm{~cm}$. This propellant strand was then kept for curing.

\section{With Catalyst [Iron (III) Oxide (Micro)]}

Table 1. Ratio of propellants prepared.

\begin{tabular}{cccccc}
\hline Propellant & AP(\%) & IO(\%) & HTPB(\%) & DOA(\%) & IPDC(\%) \\
\hline Mix. 1 (No Catalyst) & 80 & 0 & 20 & $5-8$ & $5-8$ \\
Mix. 2 (Micro IO) & 80 & 2 & 20 & $5-8$ & $5-8$ \\
Mix. 3 (Nano IO) & 80 & 2 & 20 & $5-8$ & $5-8$ \\
Mix. 4 (Flower shaped IO) & 80 & 2 & 20 & $5-8$ & $5-8$ \\
\hline
\end{tabular}


Total $=14 \mathrm{~g}$

Step 1: Ammonium Perchlorate was taken and weighed.

$\mathrm{AP}=11.2 \mathrm{~g}(80 \%$ of total $)$

Step 2: The catalyst was added to the weighed AP.

Iron Oxide $=0.224 \mathrm{~g}(2 \%$ of AP)

Step 3: The above was mixed in a dry mixer to obtain a uniform mixture.

Step 4: HTPB was added to the weighed AP. Then, to this mixture plasticizer (DOA) and curing agent (IPDC) were added.

$\mathrm{HTPB}=2.52 \mathrm{~g}(20 \%$ of total $)$

$\mathrm{DOA}=0.143 \mathrm{~g}(5 \%-8 \%$ of HTPB $)$

IPDC $=0.151 \mathrm{~g}(5 \%-8 \%$ of HTPB $)$

Step 5: The above mixture was then mixed by the process of wet mixing. It is then injected into straws of length $4 \mathrm{~cm}$. This propellant strand was then kept for curing.

3. With Catalyst [Iron (III) Oxide (Nano)]

Total $=10 \mathrm{~g}$

Step 1: Ammonium Perchlorate was taken and weighed.

$\mathrm{AP}=8 \mathrm{~g}(80 \%$ of total $)$

Step 2: The catalyst was added to the weighed AP.

Iron Oxide $=0.16 \mathrm{~g}(2 \%$ of $\mathrm{AP})$

Step 3: The above mixture was mixed in a dry mixer to obtain a uniform mixture.

Step 4: HTPB was added to the weighed AP. Then, to this mixture plasticizer (DOA) and curing agent (IPDC) were added.

$\mathrm{HTPB}=2 \mathrm{~g}(20 \%$ of total $)$

$\mathrm{DOA}=0.1 \mathrm{~g}(5 \%-8 \%$ of $\mathrm{HTPB})$

IPDC $=0.13 \mathrm{~g}(5 \%-8 \%$ of HTPB $)$

Step 5: The above mixture was then mixed by the process of wet mixing. It is then injected into straws of length $4 \mathrm{~cm}$. This propellant strand was then kept for curing.

4. With catalyst [Iron (III) Oxide (Flower Shaped)]

Total $=12 \mathrm{~g}$

Step 1: Ammonium Perchlorate was taken and weighed.

$\mathrm{AP}=9.4 \mathrm{~g}(80 \%$ of total $)$

Step 2: The catalyst was added to the weighed AP.

Iron Oxide $=0.192 \mathrm{~g}(2 \%$ of AP $)$

Step 3: The above mixture was mixed in a dry mixer to obtain a uniform mixture.

Step 4: HTPB was added to the weighed AP. Then, to this mixture plasticizer (DOA) and curing agent (IPDC) were added.

$\mathrm{HTPB}=2.18 \mathrm{~g}(20 \%$ of total $)$

$\mathrm{DOA}=0.12 \mathrm{~g}(5 \%-8 \%$ of HTPB $)$

IPDC $=0.12 \mathrm{~g}(5 \%-8 \%$ of $\mathrm{HTPB})$ 
Step 5: The above mixture was then mixed by the process of wet mixing. It is then injected into straws of length $4 \mathrm{~cm}$. This propellant strand was then kept for curing. The list of Propellants prepared are listed in Table 2.

The propellant strands were kept in an open environment for a period of about 2 - 3 days for atmospheric curing to take place. It was then placed in the curing oven for a period of one week so that further curing takes place. The obtained cured strands were placed in a strand burner for the combustion process. The strands were investigated for their atmospheric burn rate measurements. The measurements were obtained using custom made 3 fuse-wire system integrated with a data acquisition system. A custom made nichrome-ignition set up was used to initiate combustion. The combustion process was recorded using Dino-Lite long range microscope [10]-[16]. The cured propellants are shown in Figure 3.

\section{Results and Discussion}

The data obtained from the data acquisition system contained time (seconds) and voltage (volts). Burn rate was calculated for different pressures such as 30 bar, 50 bar and 70 bar. The graph gives the variation of voltage versus time in which the propellant is burnt. For various pressures the burn rate was calculated and from the obtained values the graph was plotted. The graphs obtained from the fuse wire method for different pressures are shown in Figures 4-6.

Table 2. List of propellants prepared.

\begin{tabular}{cccccc}
\hline Propellant & AP $(\mathrm{gm})$ & IO $(\mathrm{gm})$ & HTPB $(\mathrm{gm})$ & DOA $(\mathrm{gm})$ & IPDC $(\mathrm{gm})$ \\
\hline Mix 1 (No Catalyst) & 12 & 0 & 3 & 0.16 & 0.19 \\
Mix 2 (Micro) & 11.2 & 0.258 & 2.508 & 0.143 & 0.151 \\
Mix 3 (Nano) & 8 & 0.16 & 2 & 0.11 & 0.139 \\
Mix 4 (Flower) & 9.4 & 0.196 & 2.18 & 0.118 & 0.118 \\
\hline
\end{tabular}

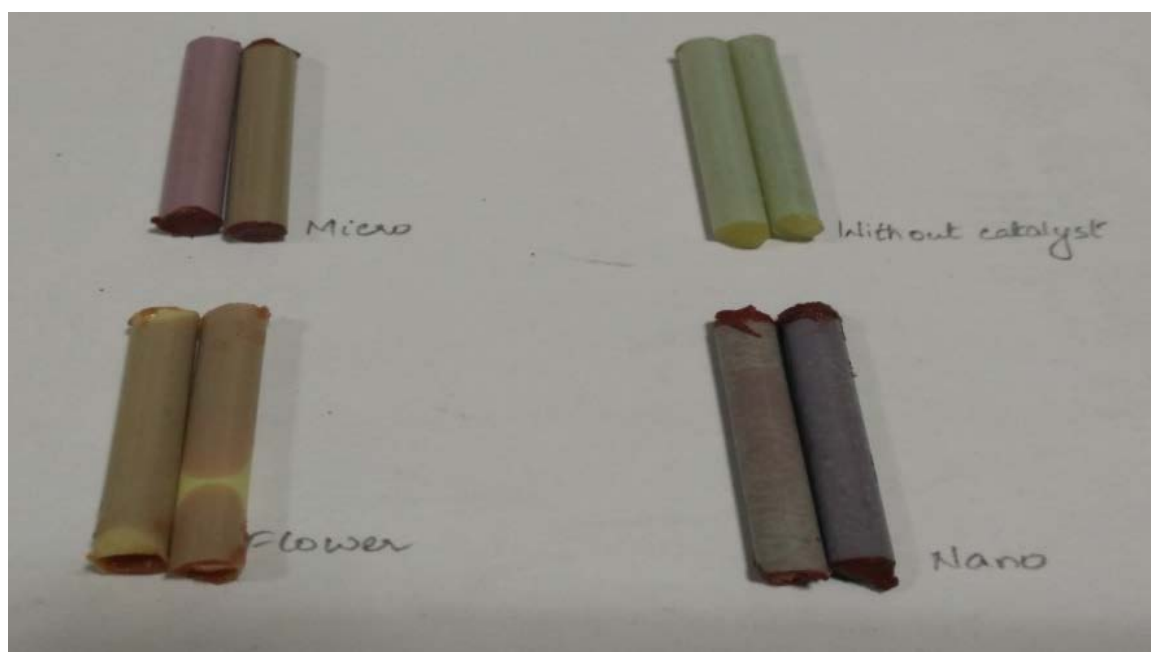

Figure 3. Solid propellant strands of various Iron Oxide catalyst. 


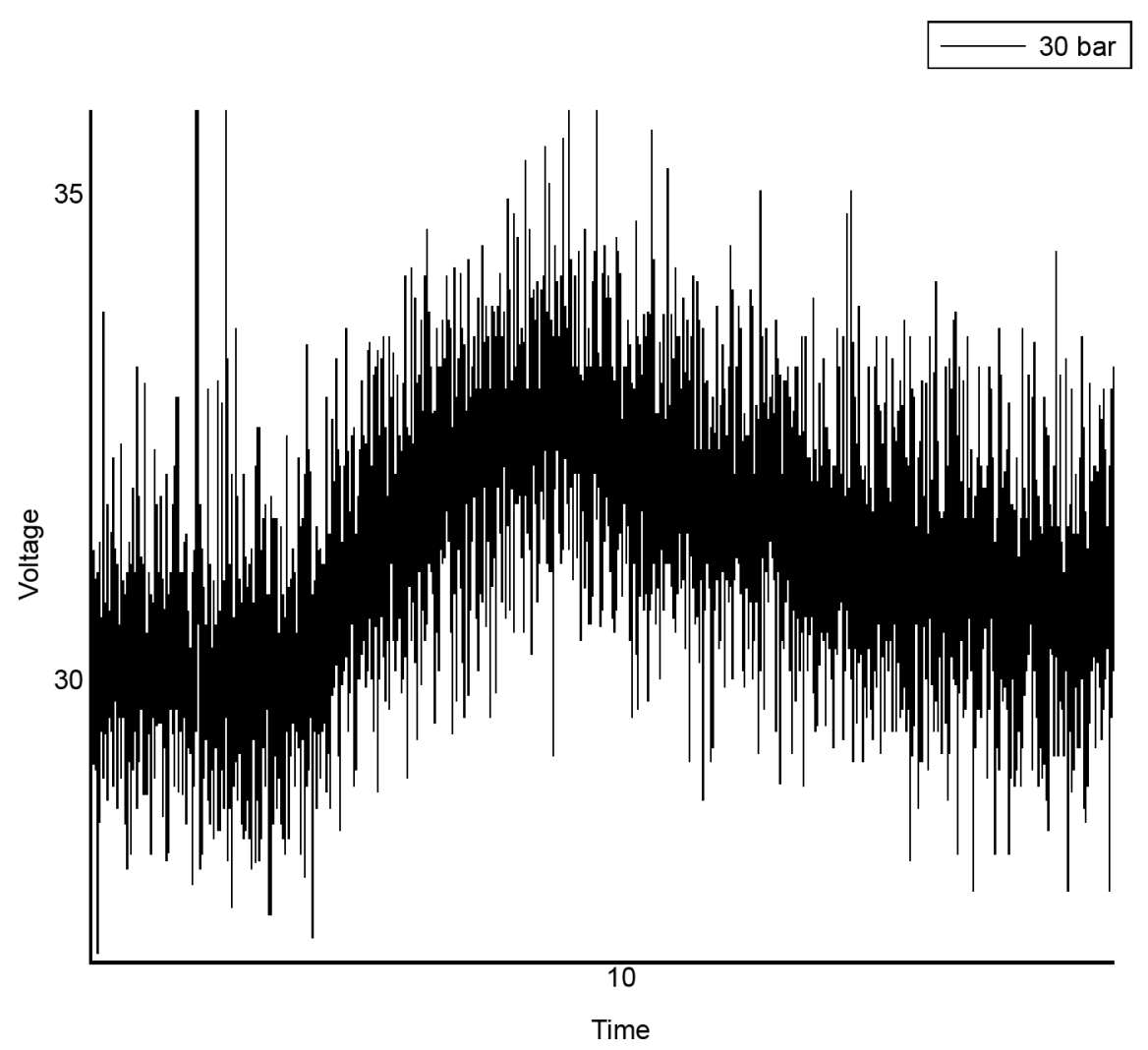

Figure 4. Without catalyst at 30 bar.

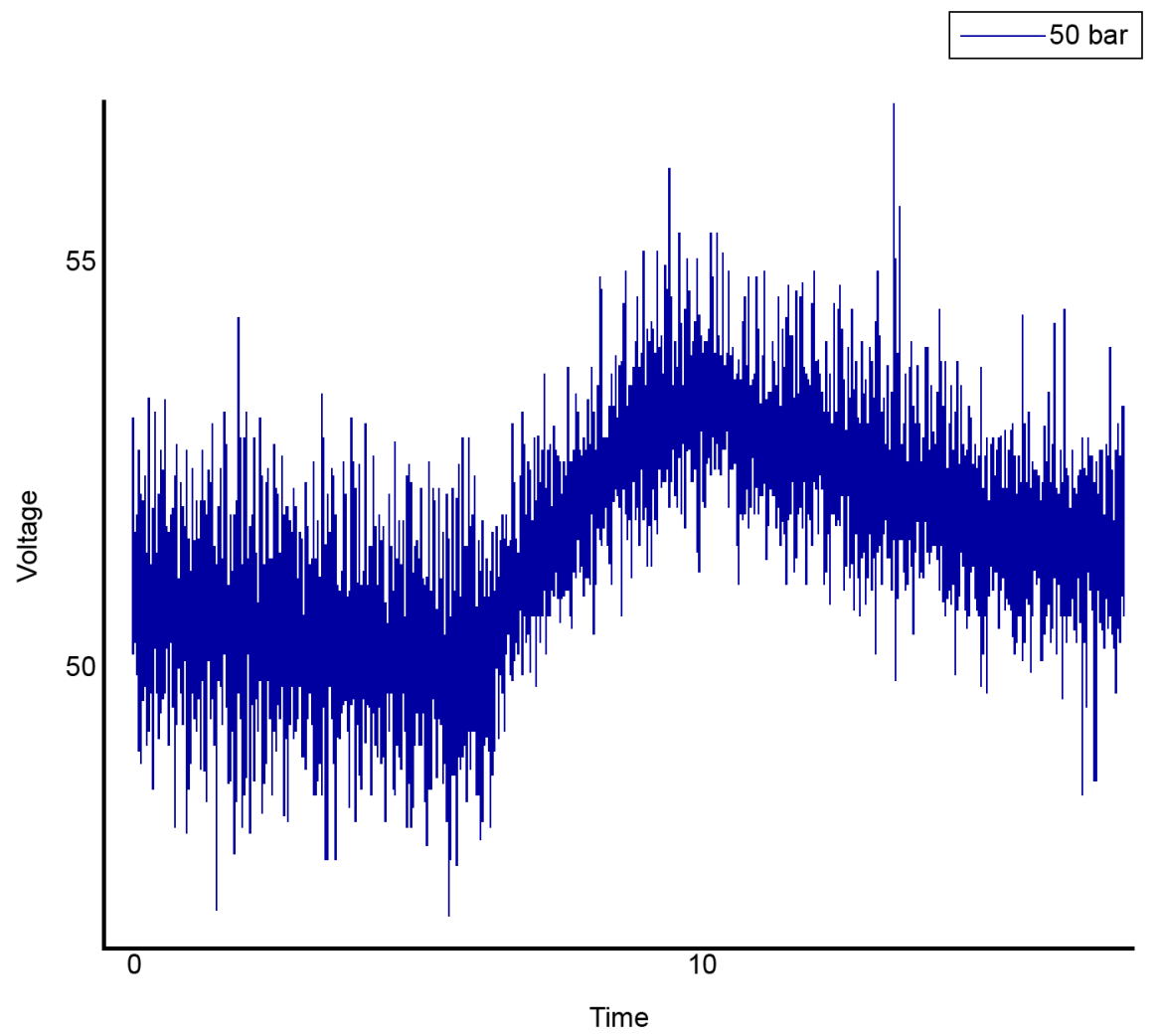

Figure 5. Without catalyst at 50 Bar. 


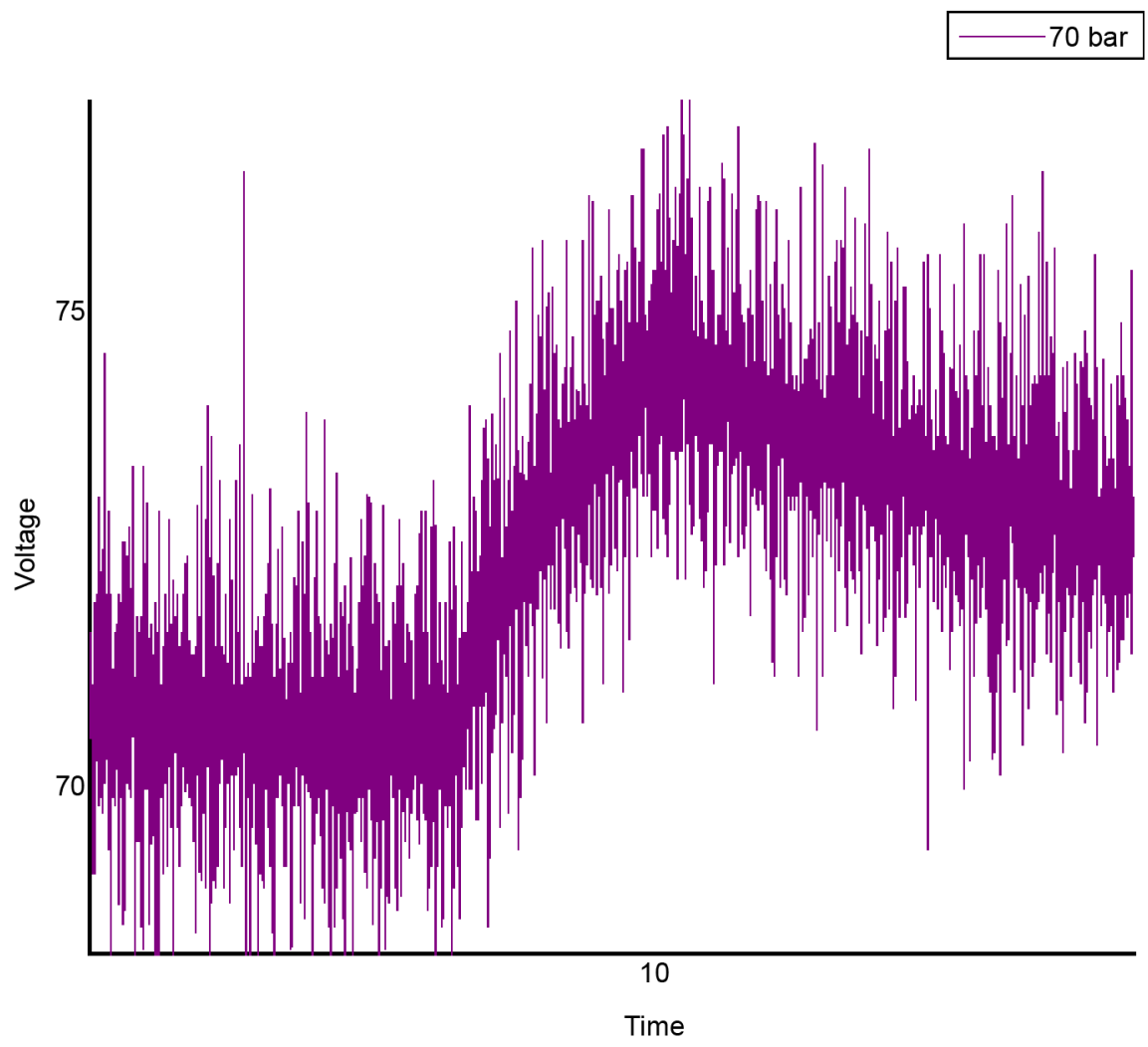

Figure 6. Without catalyst at 70 bar.

\subsection{No Catalyst}

\section{a. 30 bar:}

At 30 bar of pressure, the propellant strand was kept in the strand burner for combustion and the nature of its behaviour was tracked by the data acquisition system, which gave the following output in the form of graph below, in terms of voltage versus time. With the assistance of the slope, i.e. by calculating the difference between the highest and the lowest peaks and diving the total time by the obtained answer, we determined the rate of combustion of the strand in progression with time. In this case, no catalyst was used, to set a base, to find the effect of catalysts in the further tests. The pressure plays a vital role in the combustion process as the slope of resultant graph varies with pressure.

b. 50 bar.

At 50 bar of pressure, the propellant strand was kept in the strand burner for its combustion and the nature of its behaviour is tracked by the data acquisition system, which gave the following output in the form graph below, in terms of voltage versus time. With the assistance of the slope, i.e. by calculating the difference between the highest and the lowest peaks and diving the total time by the obtained answer, we determined the rate of combustion of the strand in progression with time. No catalyst was used.

c. 70 bar:

At 70 bar of pressure, the propellant strand was kept in the strand burner for 
combustion and the nature of its behaviour was tracked by the data acquisition system by which the following output in the form graph was obtained, in terms of voltage versus time. With the assistance of the slope, i.e. by calculating the difference between the highest and the lowest peaks and diving the total time by the obtained answer, we determined the rate of combustion of the strand in progression with time. We did not use any catalyst so as to compare the results with the various Iron Oxide catalysts.

d. Comparison Graph:

The graph shown in Figure 7 was obtained by plotting the outputs obtained from the data acquisition system at different pressures (30, 50 and 70 bar) and finally comparing their burn rates. We then concluded the pressure at which the burn rate is high. This initial test was conducted with the absence of any catalyst. With the assistance of the slope, i.e. by calculating the difference between the highest and the lowest peaks and diving the total time by the obtained answer, we calculated the burn rate.

\subsection{Flower Shaped Iron Oxide Catalyst}

a. 30 bar:

At 30 bar of pressure, the propellant strand was kept in the strand burner for combustion and the nature of its behaviour was tracked by the data acquisition system, which gave the following output in the form of graph (Figure 8), in terms of voltage versus time. With the assistance of the slope, i.e. by calculating the difference between the highest and the lowest peaks and diving the total time by the obtained answer, we determined the rate of combustion of the strand in progression with time. In this case, Flower shaped catalyst form of Iron Oxide, named so because of its shape while seen under the microscope, was used just to

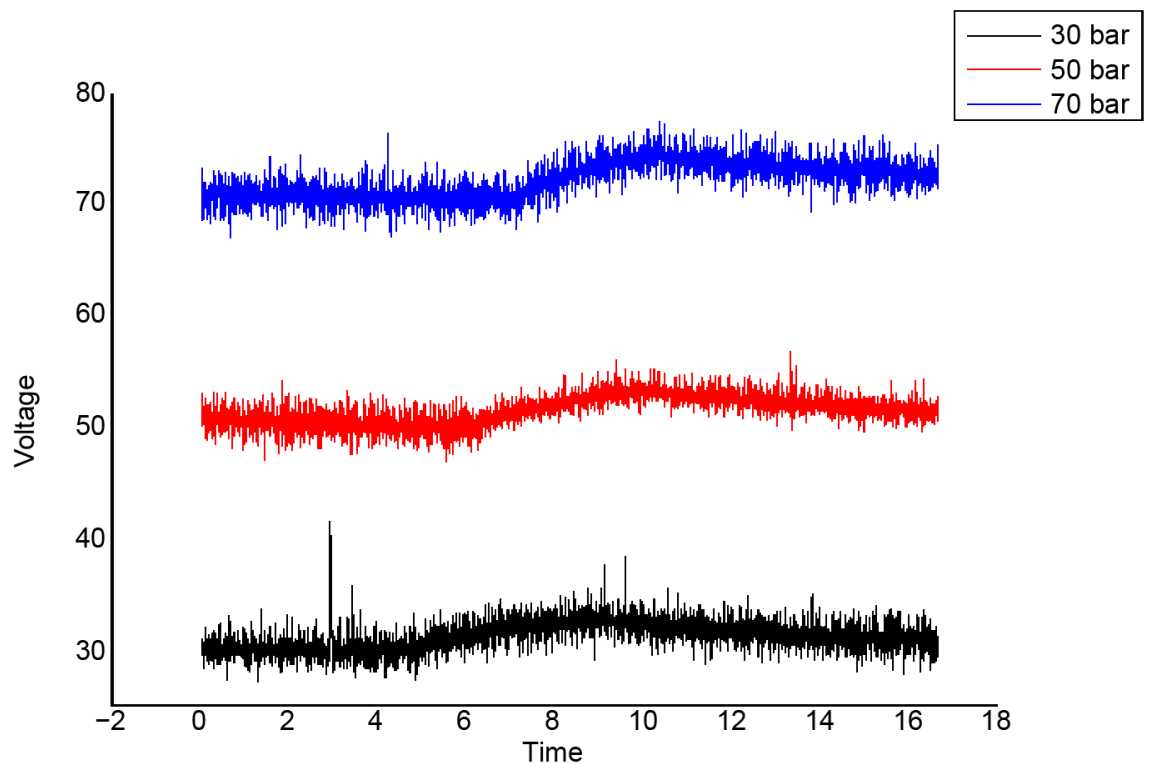

Figure 7. Comparison of various pressures of 30,50 and 70 bar in the absence of a catalyst. 


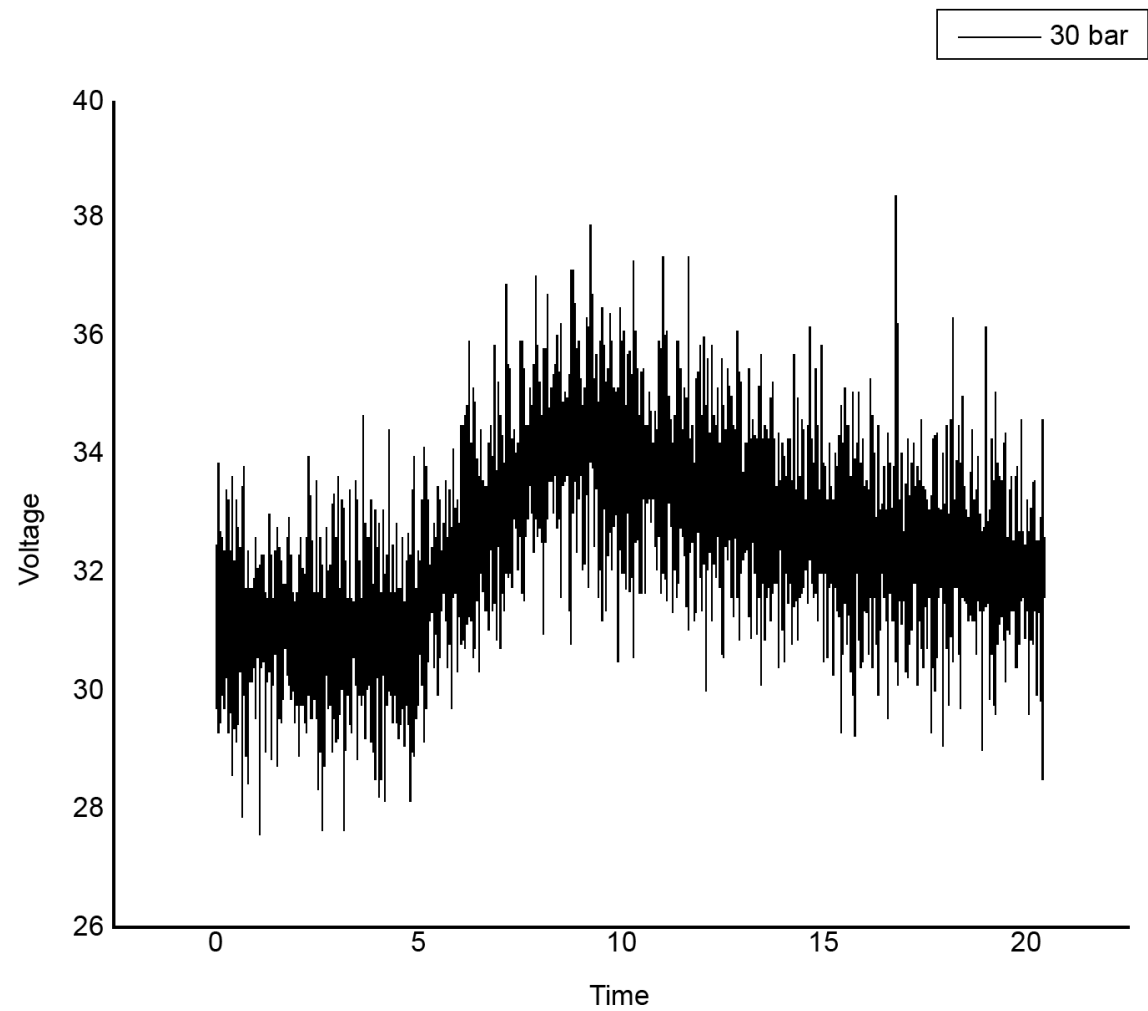

Figure 8. Iron Oxide (flower) at 30 bar.

find the effect of the catalyst in the tests. The pressure plays a vital role in the combustion process as the slope of resultant varies with pressure.

b. 50 bar:

At 50 bar of pressure, the propellant strand was kept in the strand burner for combustion and the nature of its behaviour was tracked by the data acquisition system, which gave the following output in the form of graph (Figure 9), in terms of voltage versus time. With the assistance of the slope, i.e. by calculating the difference between the highest and the lowest peaks and diving the total time by the obtained answer, we determined the rate of combustion of the strand in progression with time. In this case, the catalyst showed improvement in the burn rate compared to the $30 \mathrm{bar}$, which was inferred from the resultant output graph.

c. 70 bar:

At 70 bar of pressure, the propellant strand was kept in the strand burner for combustion and the nature of its behaviour was tracked by the data acquisition system, which gave the following output in the form of graph (Figure 10), in terms of voltage versus time. With the assistance of the slope, i.e. by calculating the difference between the highest and the lowest peaks and diving the total time by the obtained answer, we determined the rate of combustion of the strand in progression with time. In this case, the catalyst was subjected to the maximum pressure to find the effect of catalyst on the experimental setup. It was found that the burn rate was the highest at 70 bar while compared to 30 and 50 bar.

d. Comparison Graph: 


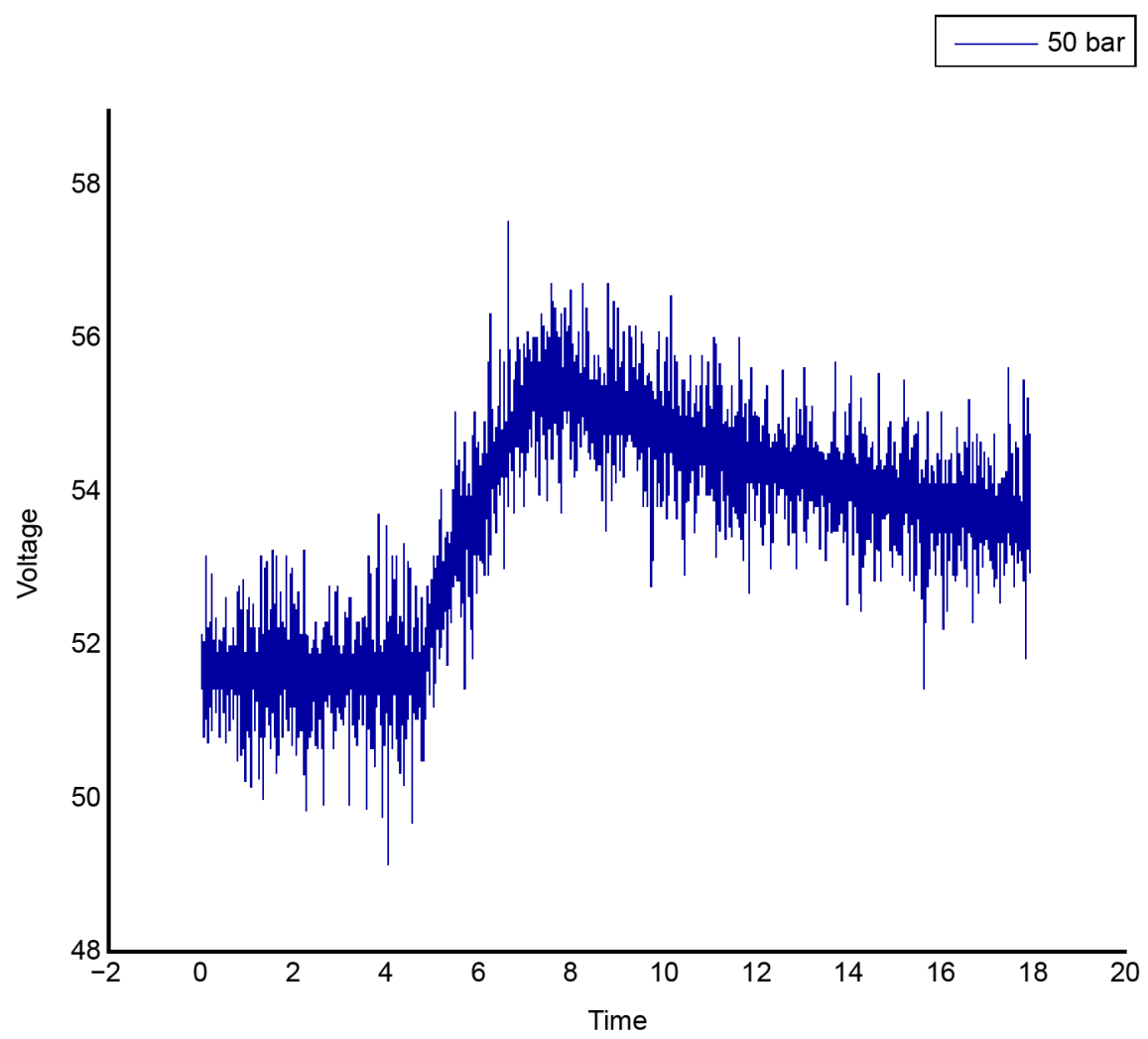

Figure 9. Iron Oxide (flower) at 50 bar.

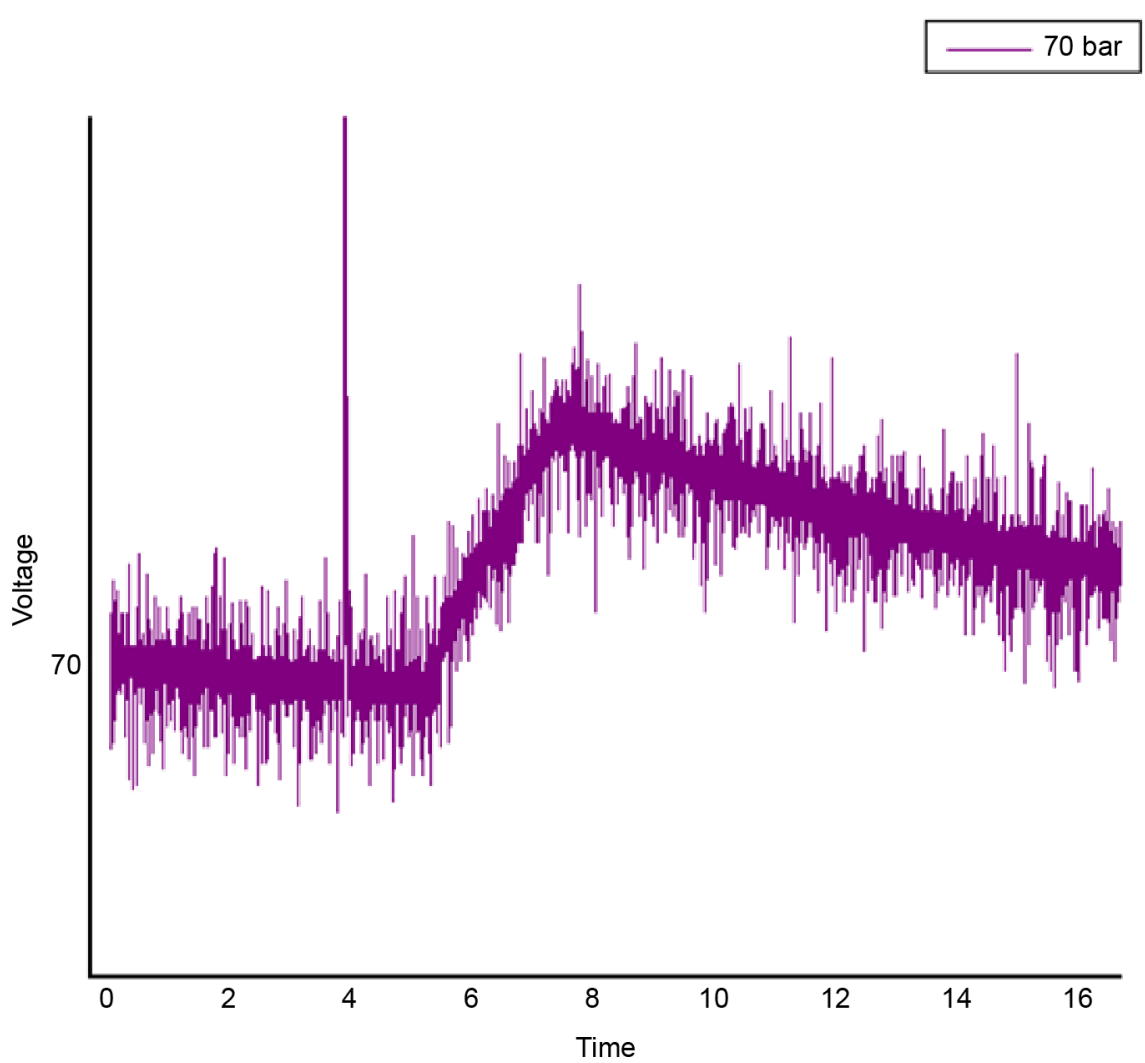

Figure 10. Iron Oxide (flower) at 70 bar. 
The graph shown in Figure 11 was obtained by plotting the outputs obtained from the data acquisition system at different pressures (30,50 and 70 bar) and finally comparing their burn rates. We then concluded the pressure at which the burn rate is high. This test was conducted with the Flower shaped catalyst. With the assistance of the slope, i.e. by calculating the difference between the highest and the lowest peaks and diving the total time by the obtained answer, we calculated the burn rate.

\subsection{Nano Iron Oxide}

a. 30 bar:

At 30 bar of pressure, the propellant strand was kept in the strand burner for combustion and the nature of its behaviour was tracked by the data acquisition system, which gave the following output in the form of graph (Figure 12), in terms of voltage versus time. With the assistance of the slope, i.e. by calculating the difference between the highest and the lowest peaks and diving the total time by the obtained answer, we determined the rate of combustion of the strand in progression with time. In this case, Nano form of Iron Oxide catalyst was used just to find the effect of catalyst in the tests. The pressure plays a vital role in the combustion process as the slope of the resultant varies.

b. 50 bar:

At 50 bar of pressure, the propellant strand was kept in the strand burner for combustion and the nature of its behaviour was tracked by the data acquisition

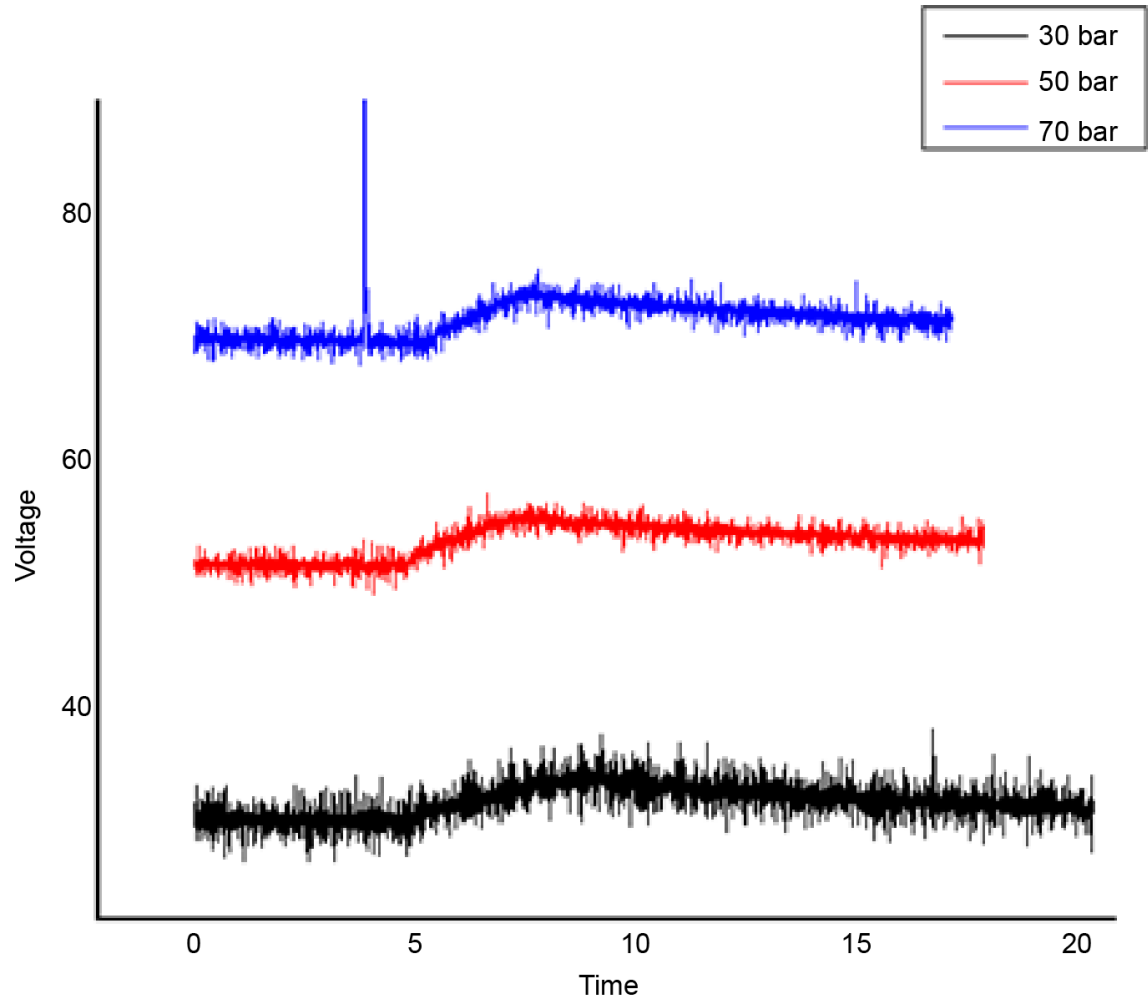

Figure 11. Comparison of various pressures of 30, 50 and 70 bar for Iron Oxide (flower). 


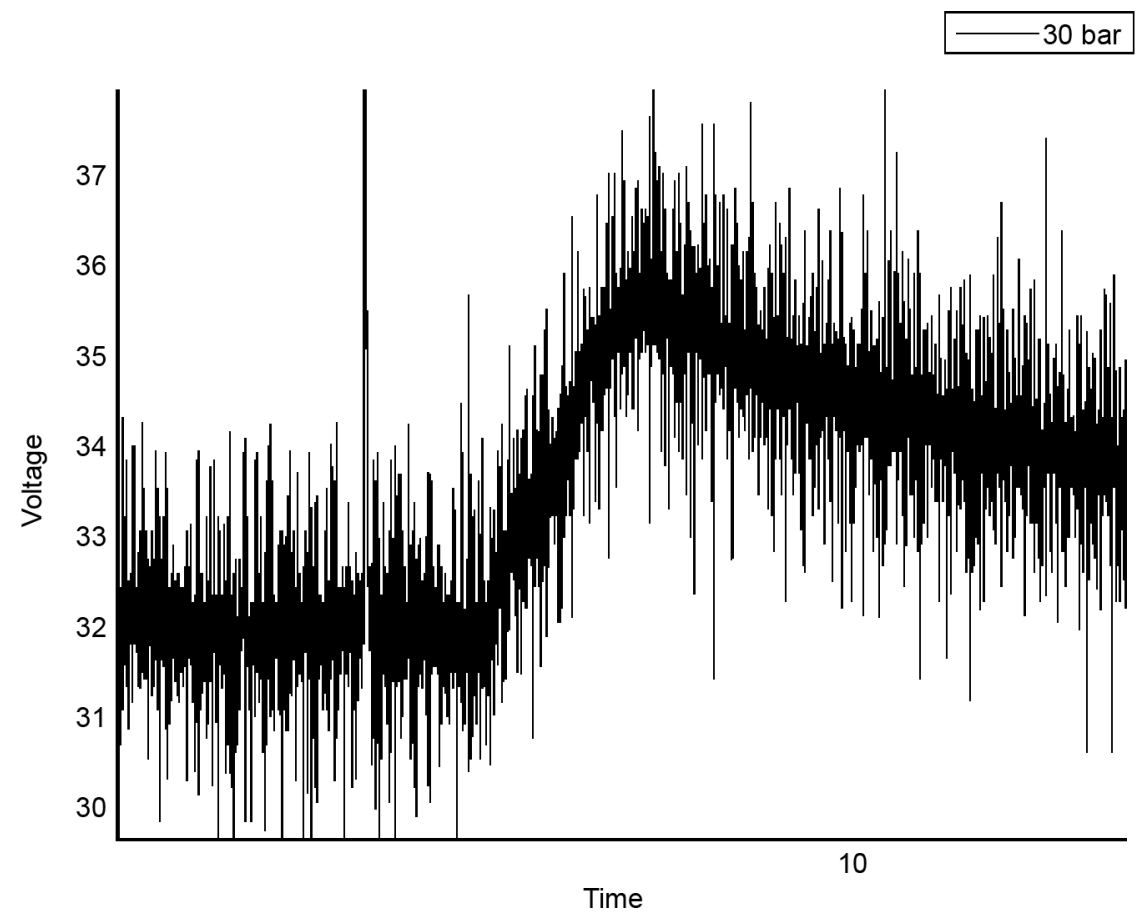

Figure 12. Iron Oxide (nano) at 30 bar.

system, which gave the following output in the form of graph (Figure 13), in terms of voltage versus time. With the assistance of the slope, i.e. by calculating the difference between the highest and the lowest peaks and diving the total time by the obtained answer, we determined the rate of combustion of the strand in progression with time. In this case, the catalyst showed improvement in the burn rate compared to the $30 \mathrm{bar}$, which was inferred from the resultant output graph.

c. 70 bar:

At 70 bar of pressure, the propellant strand was kept in the strand burner for combustion and the nature of its behaviour was tracked by the data acquisition system, which gave the following output in the form of graph (Figure 14), in terms of voltage versus time. With the assistance of the slope, i.e. by calculating the difference between the highest and the lowest peaks and diving the total time by the obtained answer, we determined the rate of combustion of the strand in progression with time. In this case, the catalyst was subjected to the maximum pressure to find the effect of catalyst on the experimental setup. It was found that the burn rate was the highest at 70 bar while compared to 30 and 50 bar.

\section{d. Comparison Graph:}

The graph shown in Figure 15 was obtained by plotting the outputs obtained from the data acquisition system at different pressures (30,50 and 70 bar) and finally comparing their burn rates. We then concluded the pressure at which the burn rate is high. This test was conducted with the Nano catalyst. With the assistance of the slope, i.e. by calculating the difference between the highest and the lowest peaks and diving the total time by the obtained answer, we calculated the burn rate. 


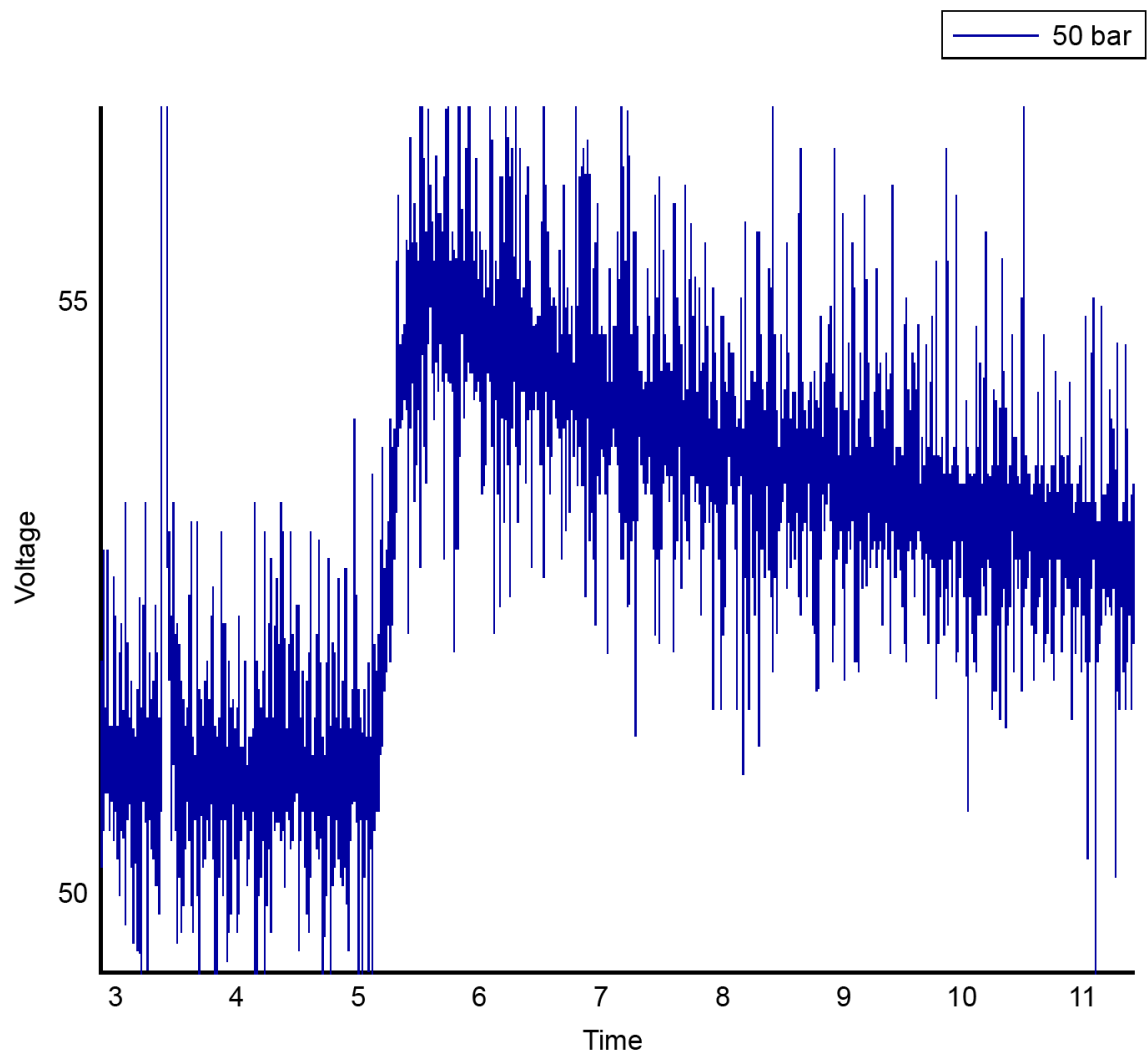

Figure 13. Iron Oxide (nano) at 50 Bar.

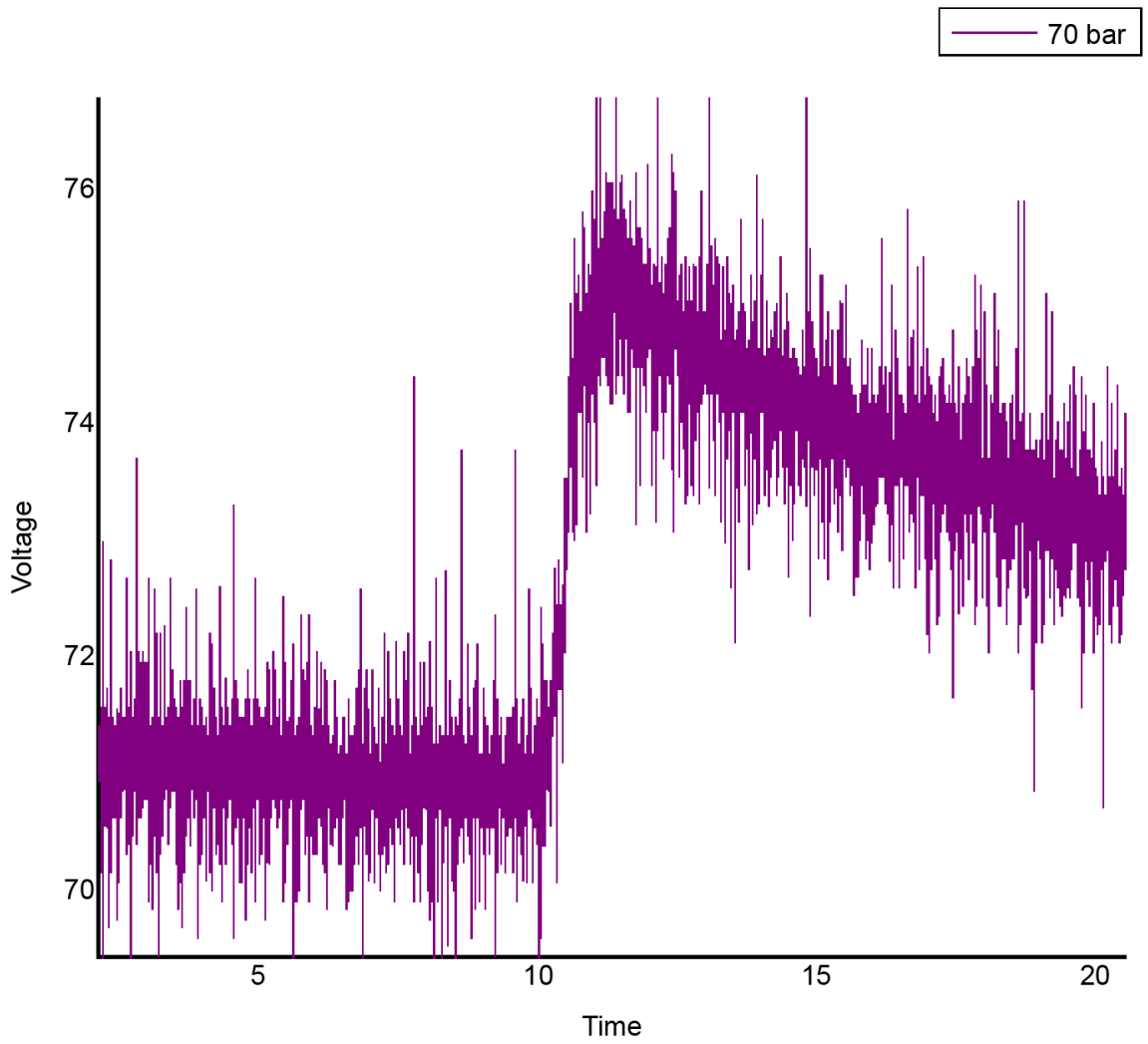

Figure 14. Iron Oxide (nano) at 70 Bar. 


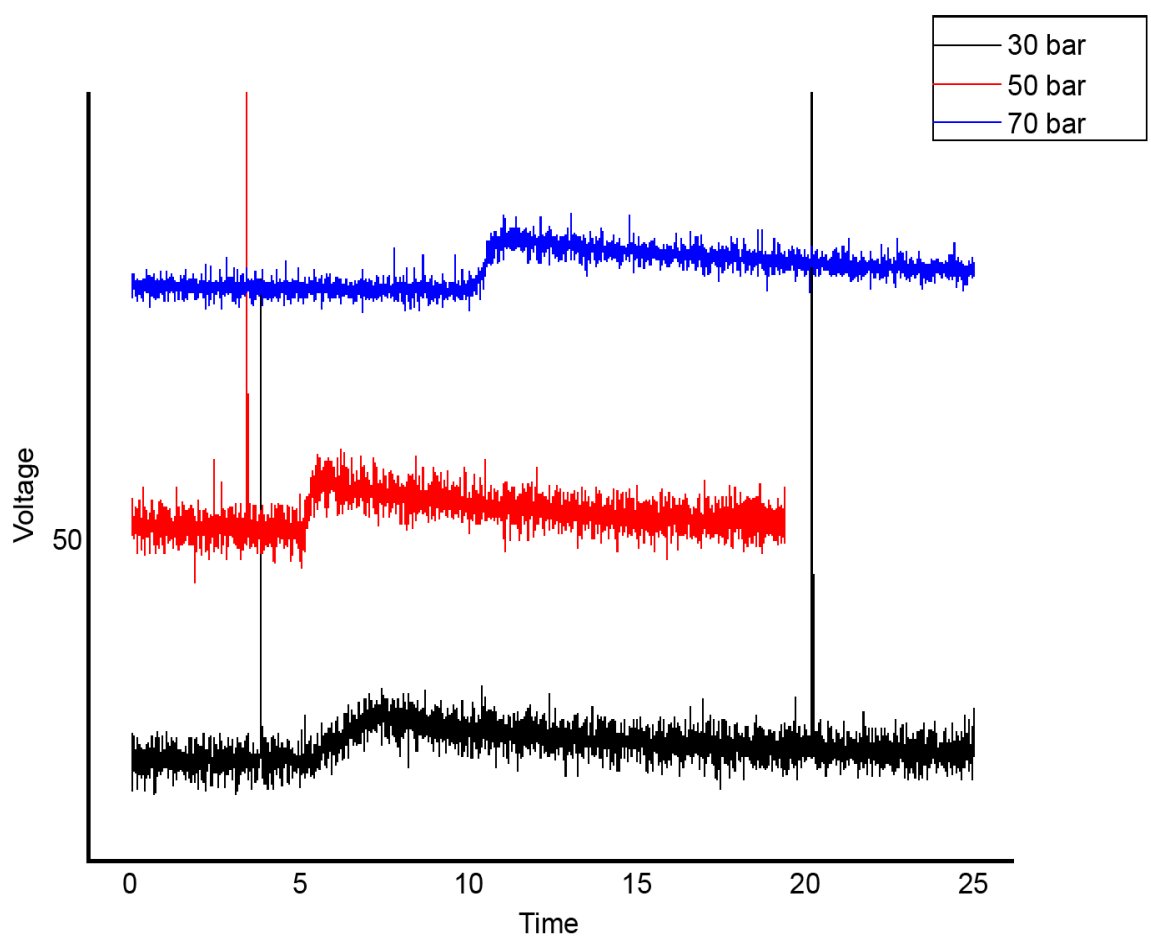

Figure 15. Comparison of various pressures of 30, 50 and 70 bar for Iron Oxide (nano).

\subsection{Micro Iron Oxide}

\section{a. 30 bar:}

At 30 bar of pressure, the propellant strand was kept in the strand burner for combustion and the nature of its behaviour was tracked by the data acquisition system, which gave the following output in the form of graph (Figure 16), in terms of voltage versus time. With the assistance of the slope, i.e. by calculating the difference between the highest and the lowest peaks and diving the total time by the obtained answer, we determined the rate of combustion of the strand in progression with time. In this case, Micro form of Iron Oxide catalyst was used just to find the effect of catalyst in the tests. The pressure plays a vital role in the combustion process as the slope of the resultant varies.

\section{b. 50 bar:}

At 50 bar of pressure, the propellant strand was kept in the strand burner for combustion and the nature of its behaviour was tracked by the data acquisition system, which gave the following output in the form of graph (Figure 17), in terms of voltage versus time. With the assistance of the slope, i.e. by calculating the difference between the highest and the lowest peaks and diving the total time by the obtained answer, we determined the rate of combustion of the strand in progression with time. In this case, the catalyst showed improvement in the burn rate compared to the $30 \mathrm{bar}$, which was inferred from the resultant output graph.

c. 70 bar:

At 70 bar of pressure, the propellant strand was kept in the strand burner for combustion and the nature of its behaviour was tracked by the data acquisition 


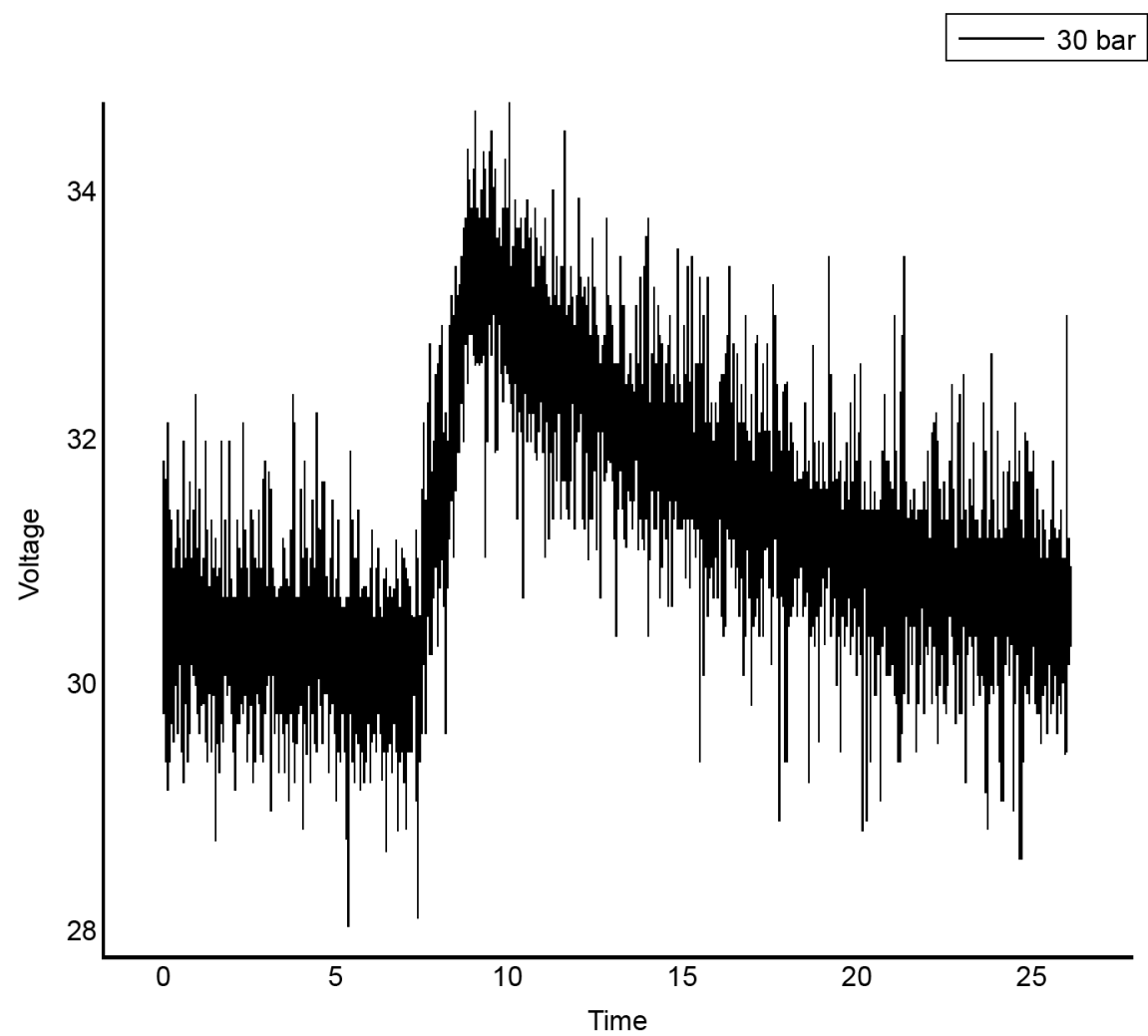

Figure 16. Iron Oxide (micro) at 30 bar.

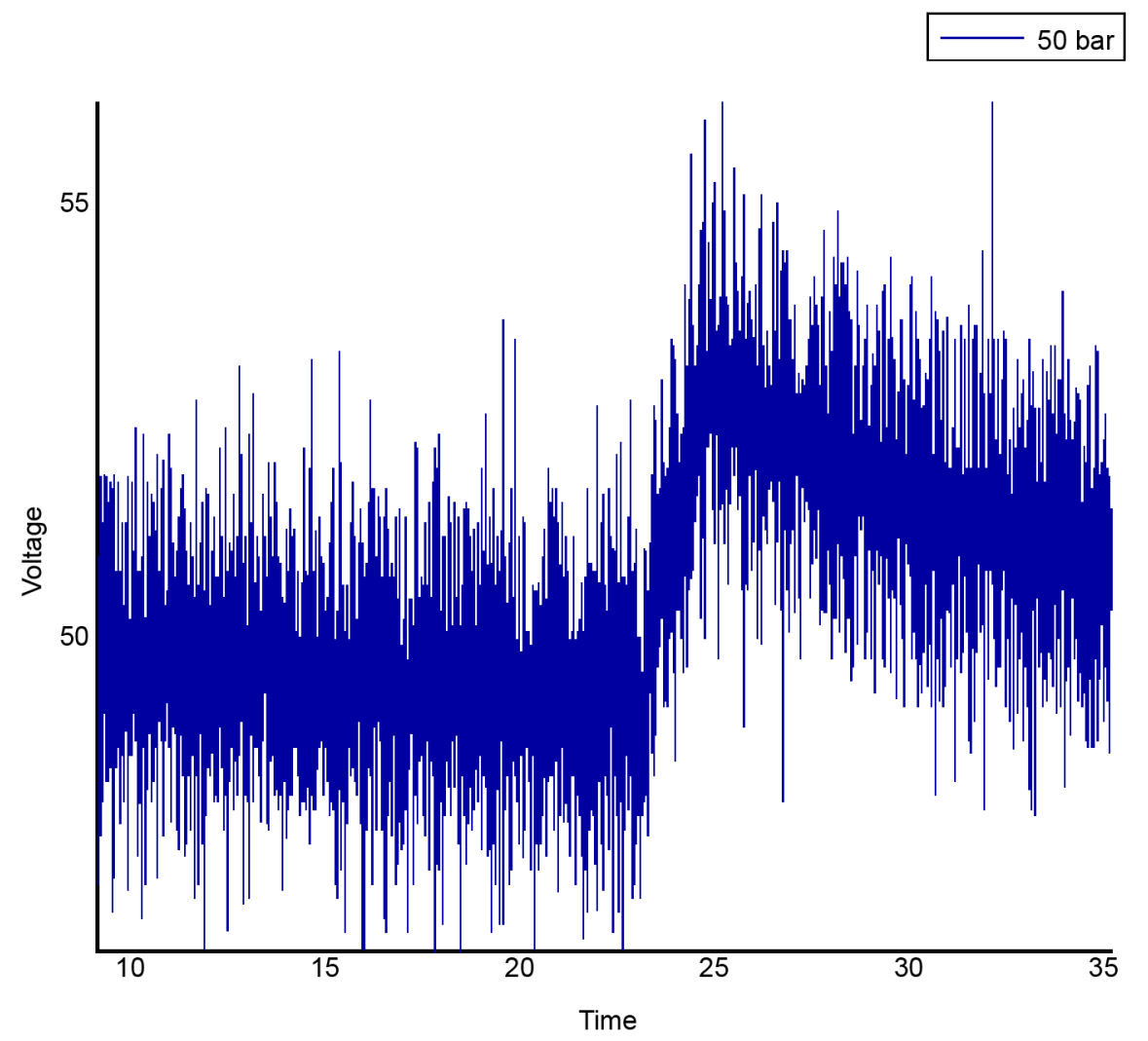

Figure 17. Iron Oxide (micro) at 50 bar. 
system, which gave the following output in the form of graph (Figure 18), in terms of voltage versus time. With the assistance of the slope, i.e. by calculating the difference between the highest and the lowest peaks and diving the total time by the obtained answer, we determined the rate of combustion of the strand in progression with time. In this case, the catalyst was subjected to the maximum pressure to find the effect of catalyst on the experimental setup. It was found that the burn rate was the highest at 70 bar while compared to 30 and 50 bar.

d. Comparison Graph:

The graph shown in Figure 19 was obtained by plotting the outputs obtained from the data acquisition system at different pressures (30,50 and 70 bar) and finally comparing their burn rates. We then concluded the pressure at which the burn rate is high. This test was conducted with the Flower shaped catalyst. With the assistance of the slope, i.e. by calculating the difference between the highest and the lowest peaks and diving the total time by the obtained answer, we calculated the burn rate.

The values of burn rate ' $r$ ' obtained with several catalysts used at various pressure are tabulated under a table which was obtained by the nature of their combustion the strand burner resulting in the slope of their combustion with its time. The values obtained from the data acquisition system are as shown in the Table 3.

The catalytic effect of $\mathrm{Fe}_{2} \mathrm{O}_{3}$ is observed mainly on high-temperature decomposition process and not on the initial stages of decomposition. The nano

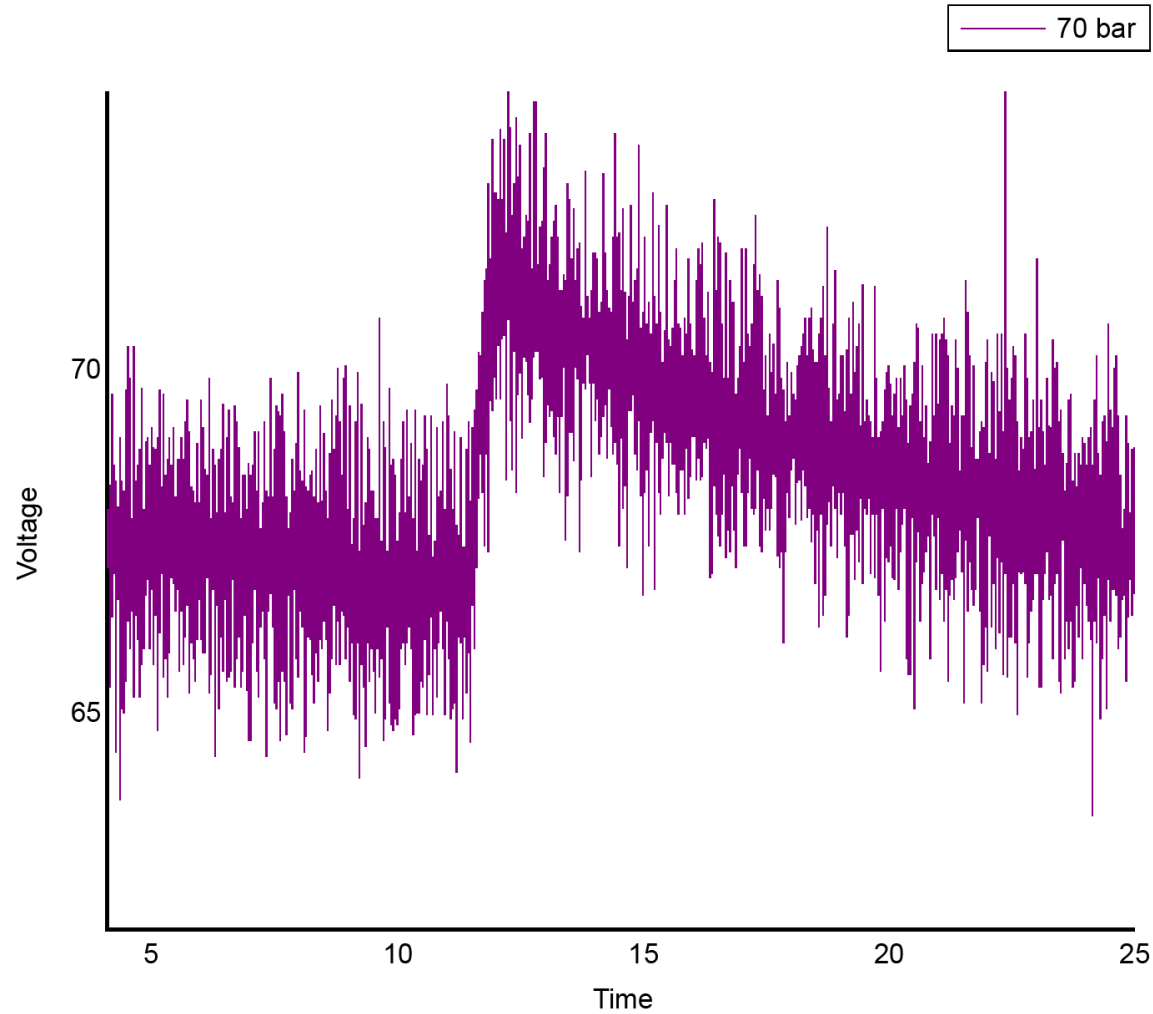

Figure 18. Iron Oxide (Micro) at 70 bar. 


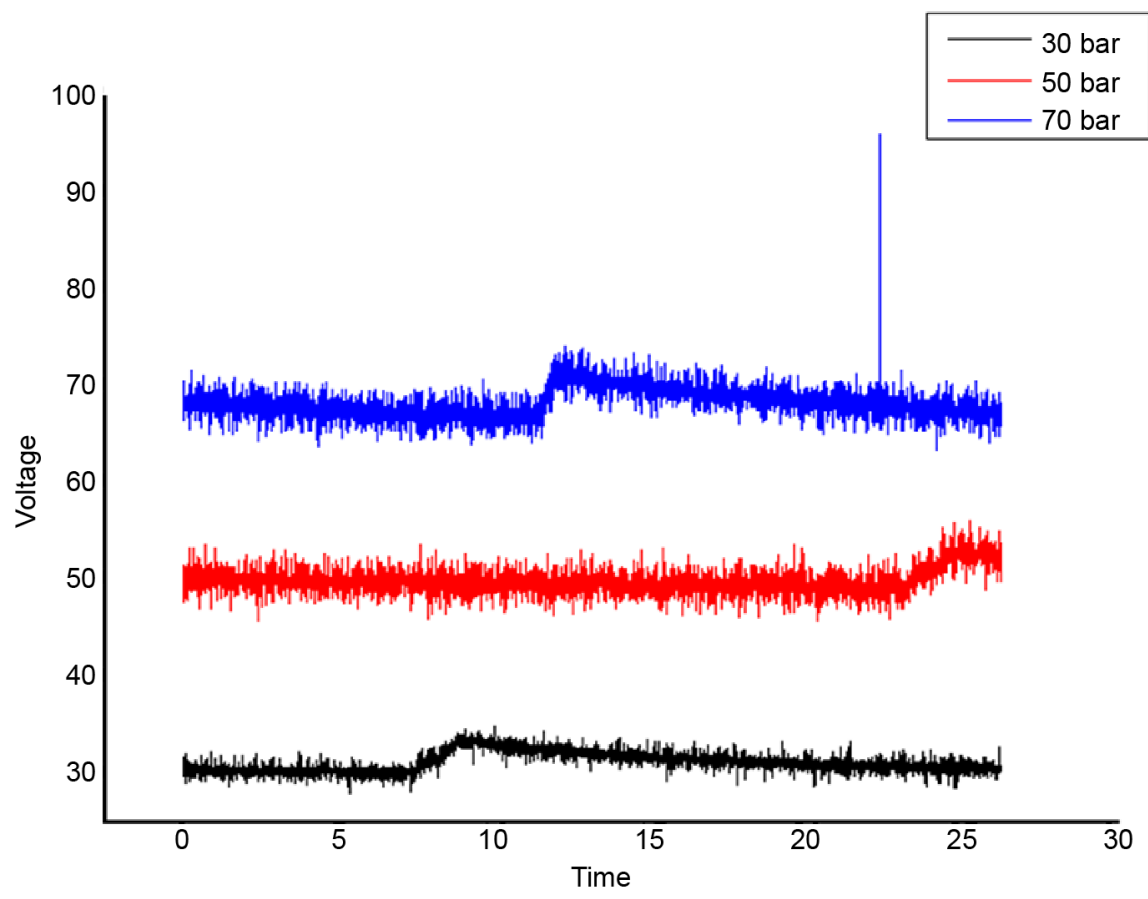

Figure 19. Comparison of various pressures of 30, 50 and 70 bar for Iron Oxide (Micro).

Table 3. Pressure and burn rate values.

\begin{tabular}{ccccccccc}
\hline $\begin{array}{c}\text { Pressure } \\
(\mathrm{Bar})\end{array}$ & \multicolumn{2}{c}{$\begin{array}{c}\text { Without Catalyst } \\
(\mathrm{Mm} / \mathrm{Sec})\end{array}$} & \multicolumn{2}{c}{$\begin{array}{c}\text { Micro } \\
(\mathrm{Mm} / \mathrm{Sec})\end{array}$} & \multicolumn{2}{c}{$\begin{array}{c}\text { Nano } \\
(\mathrm{Mm} / \mathrm{Sec})\end{array}$} & \multicolumn{2}{c}{$\begin{array}{c}\text { Flower Shaped } \\
(\mathrm{Mm} / \mathrm{Sec})\end{array}$} \\
\hline & Pressure & Fuse & Pressure & Fuse & Pressure & Fuse & Pressure & Fuse \\
\hline 30 & 5.62 & 6.9 & - & 12.98 & 15.378 & 13.157 & 8.329 & 7.299 \\
50 & 9.746 & 9.02 & - & 16.66 & 21.66 & - & 11.699 & 15.625 \\
70 & 12.326 & 11.66 & 20.408 & - & 28.776 & - & 16.827 & 18.518 \\
\hline
\end{tabular}

$\mathrm{Fe}_{2} \mathrm{O}_{3}$ affects not only the solid ammonium perchlorate but also the reactions proceeding in the gas phase. The lowering in activation energy and high temperature decomposition supports this observation and further confirms that the subsurface reactions and the reactions occurring in the gas phase are closely connected with each other. Different opinions on the mechanism of catalytic action of $\mathrm{Fe}_{2} \mathrm{O}_{3}$ exist.

The calculation was done based on the graphs obtained taking the difference between the largest and smallest values. The burn rate is measured in terms of $\mathrm{mm} / \mathrm{sec}$.

The final burn rate graph for the various catalysts at different pressure is obtained. The graph is plotted for log burn rate versus log pressure. The pressure index is calculated using the formula

$\mathrm{n}=\log$ (burn rate) $/ \log$ (pressure).

The above formula is used in calculating pressure index for various catalysts.

The calculated burn rate and the pressure applied is converted into log and the corresponding burn rate values for each pressure of 30,50 and 70 bar are 
plotted to get the value of pressure index.

\section{Without Catalyst:}

Figure 20 shows the graph of log burn rate versus log pressure for a propellant mixture in the absence of a catalyst. The pressure index obtained was 0.568.

\section{Micro Catalyst:}

Figure 21 shows the graph of log burn rate versus log pressure for the Micro form of Iron Oxide catalyst propellant mixture. The pressure index was found to be 0.727 .

\section{Nano Catalyst:}

Figure 22 shows the graph of log burn rate versus log pressure for the Nano form of Iron Oxide catalyst propellant mixture. The pressure index achieved was 0.792 .

\section{Flower Shaped Catalyst:}

Figure 23 shows the graph of log burn rate versus log pressure for a flower shaped form of Iron Oxide catalyst propellant mixture. The pressure index attained was 0.657 .

\section{Comparison Graph:}

It can be inferred from the graph which is shown in Figure 24, that Nano structured form of Iron Oxide delivers the best burn rate when compared to the rest. Micro, Flower shaped and the no catalyst form take occupy the second, third and the fourth places respectively. With Nano structured catalyst, a pressure index of 0.792 was achieved while Micro, Flower Shaped and no catalyst form delivered $0.727,0.657,0.568$ respectively which are all less compared to that of Nano structured. Hence, we conclude that the Nano structured catalysts

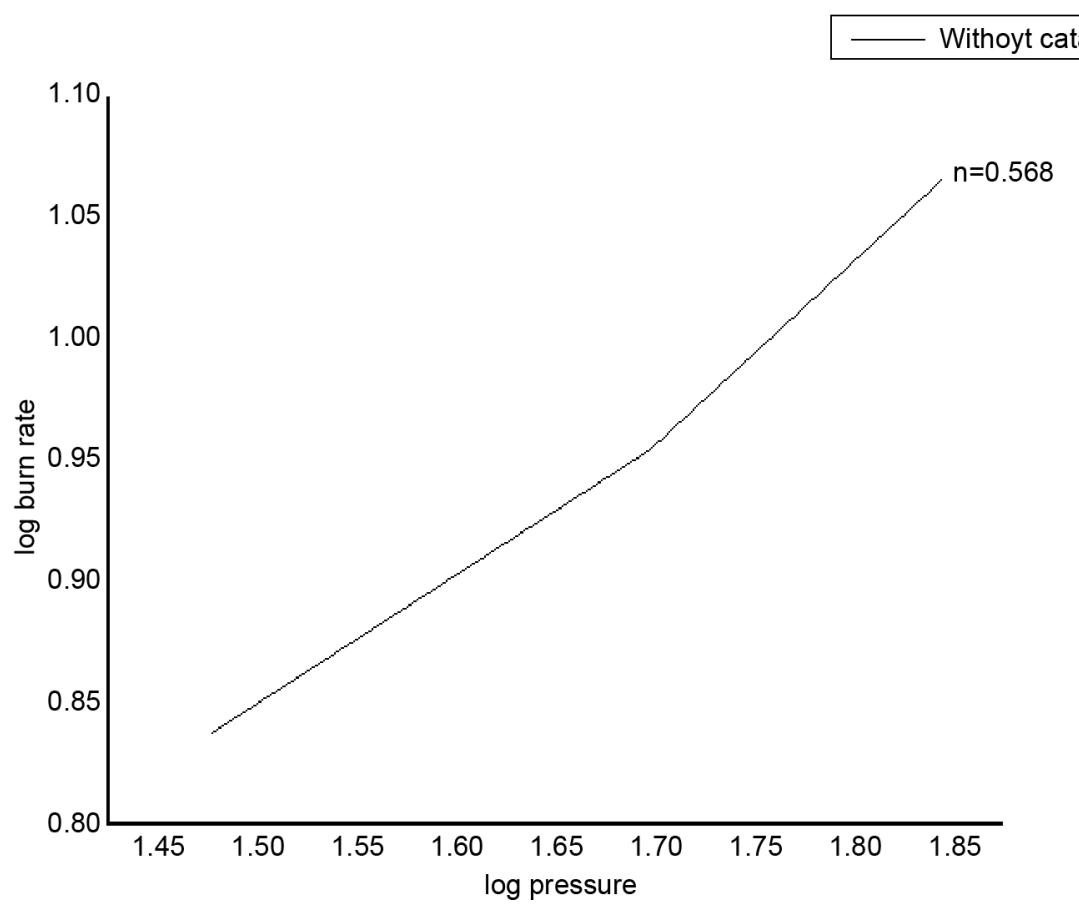

Figure 20. Log burn rate versus log pressure for without catalyst. 


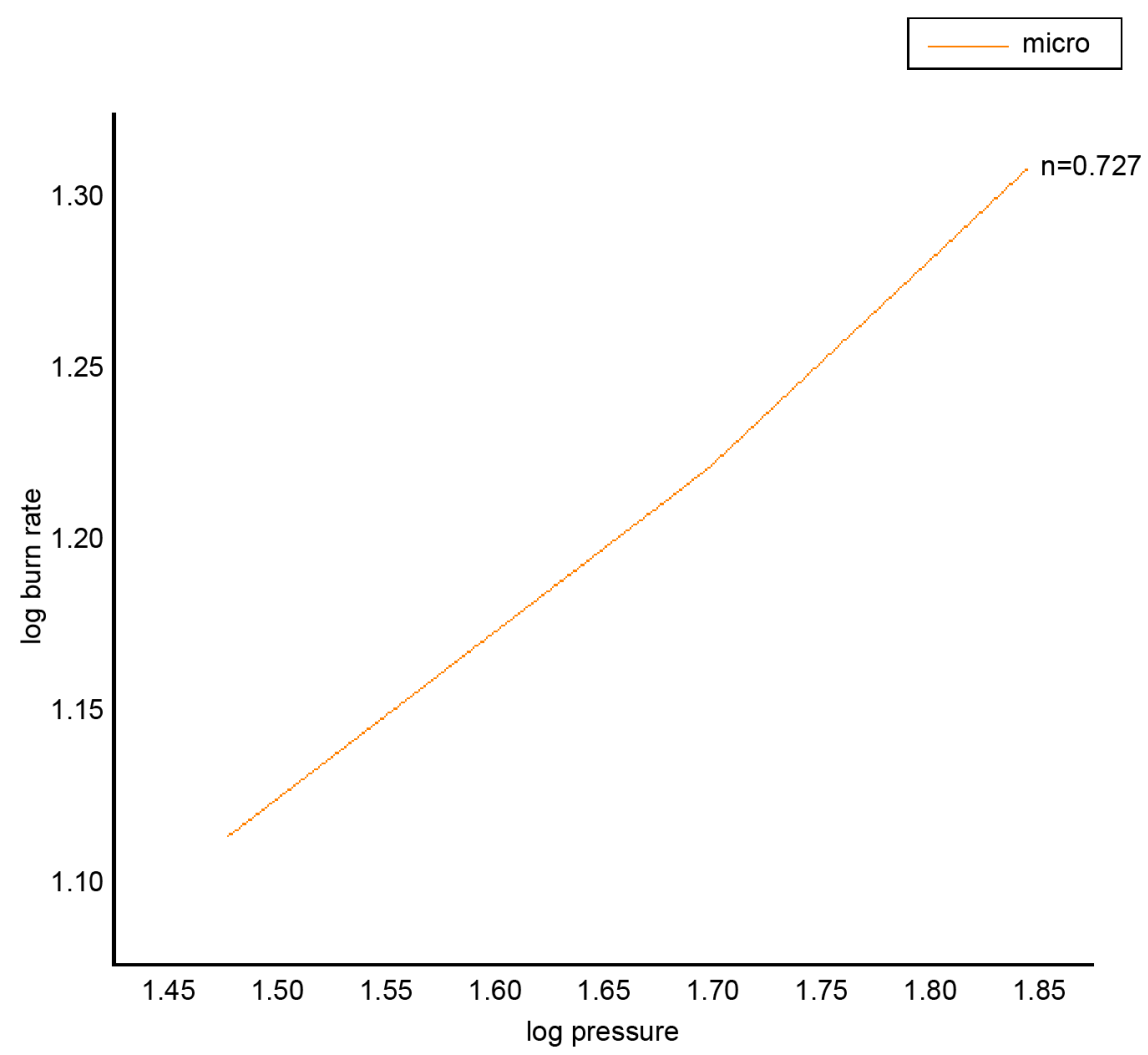

Figure 21. Log burn rate versus log pressure for micro catalyst.

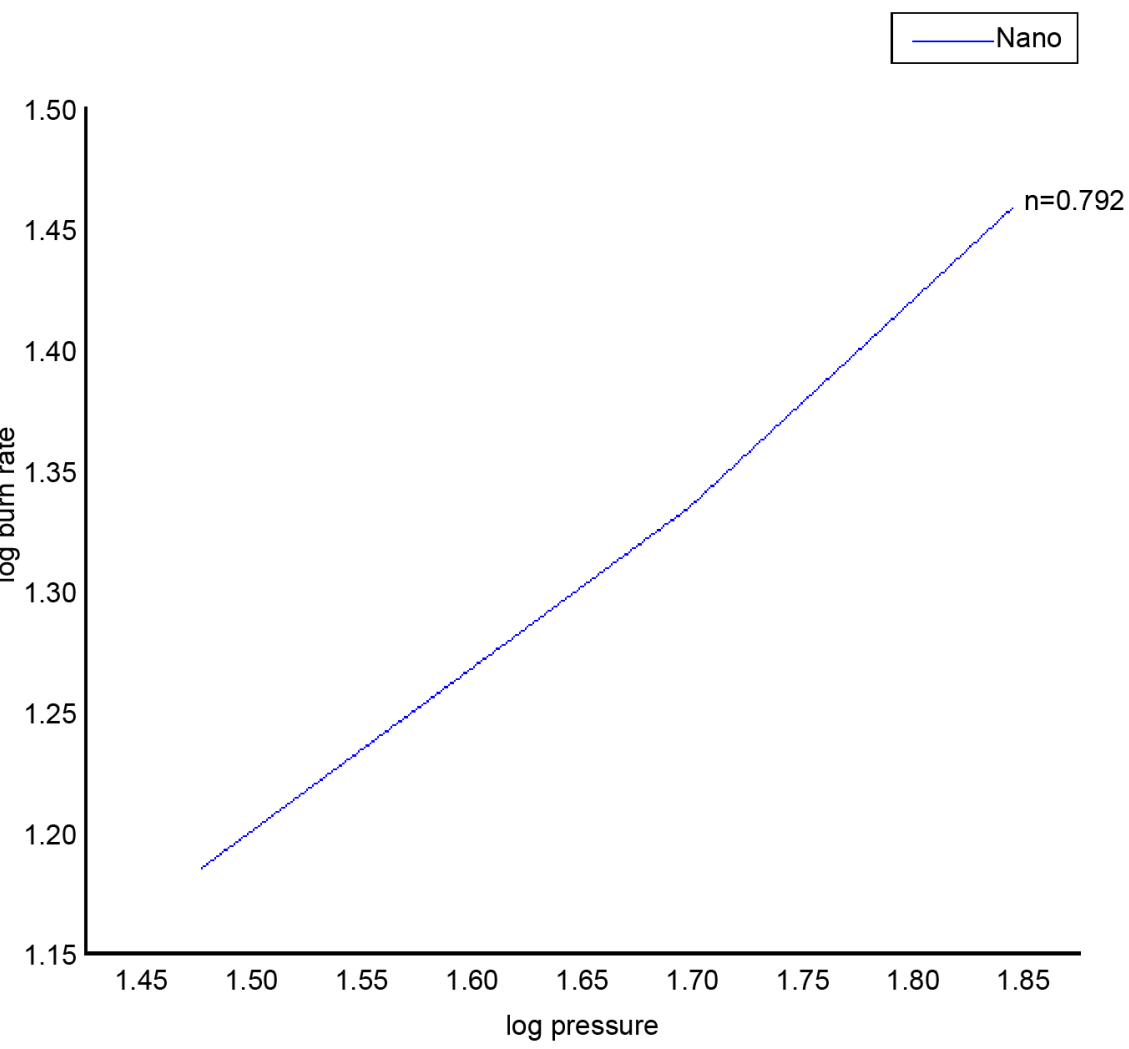

Figure 22. Log burn rate versus log pressure for nano catalyst. 


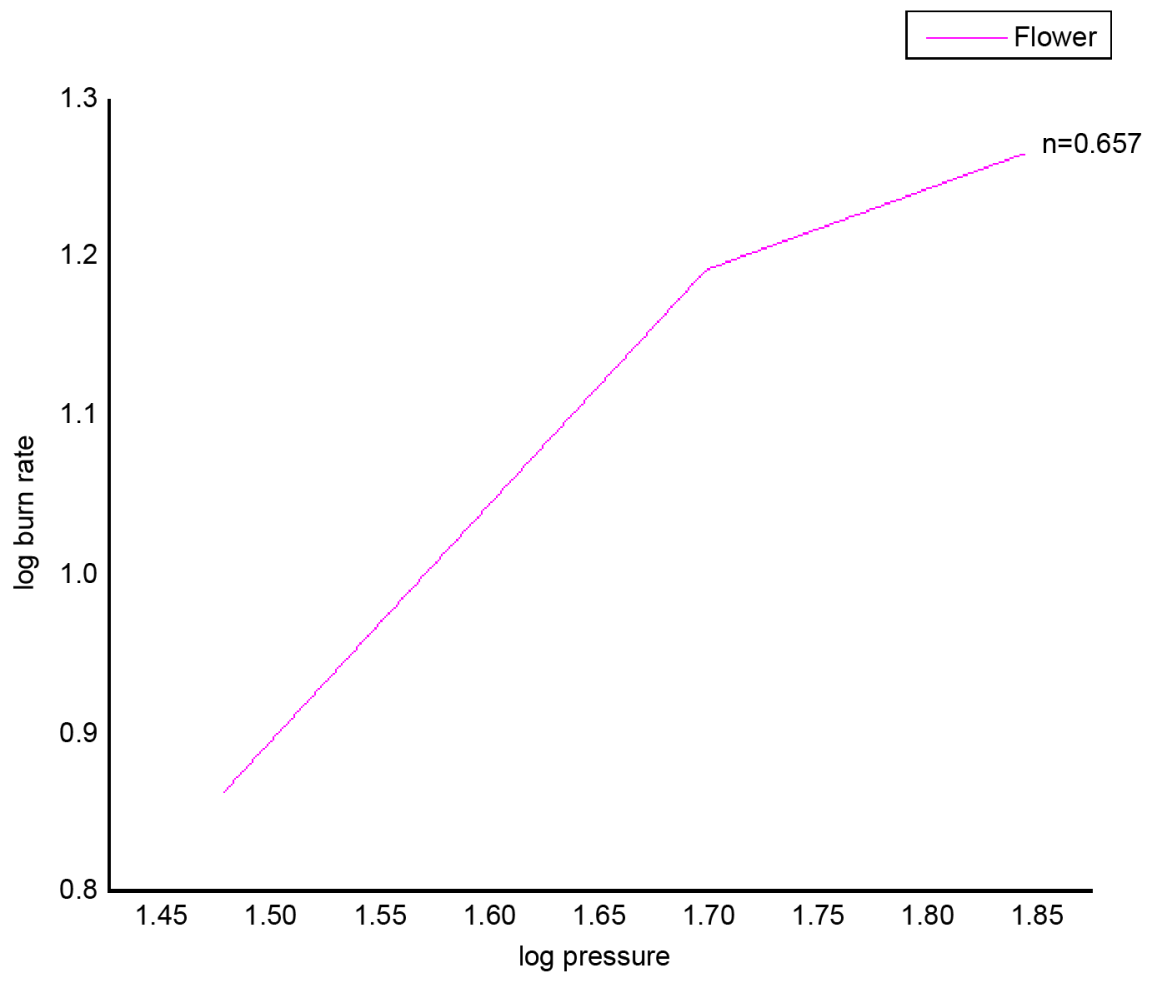

Figure 23. Log burn rate versus log pressure for flower shaped.

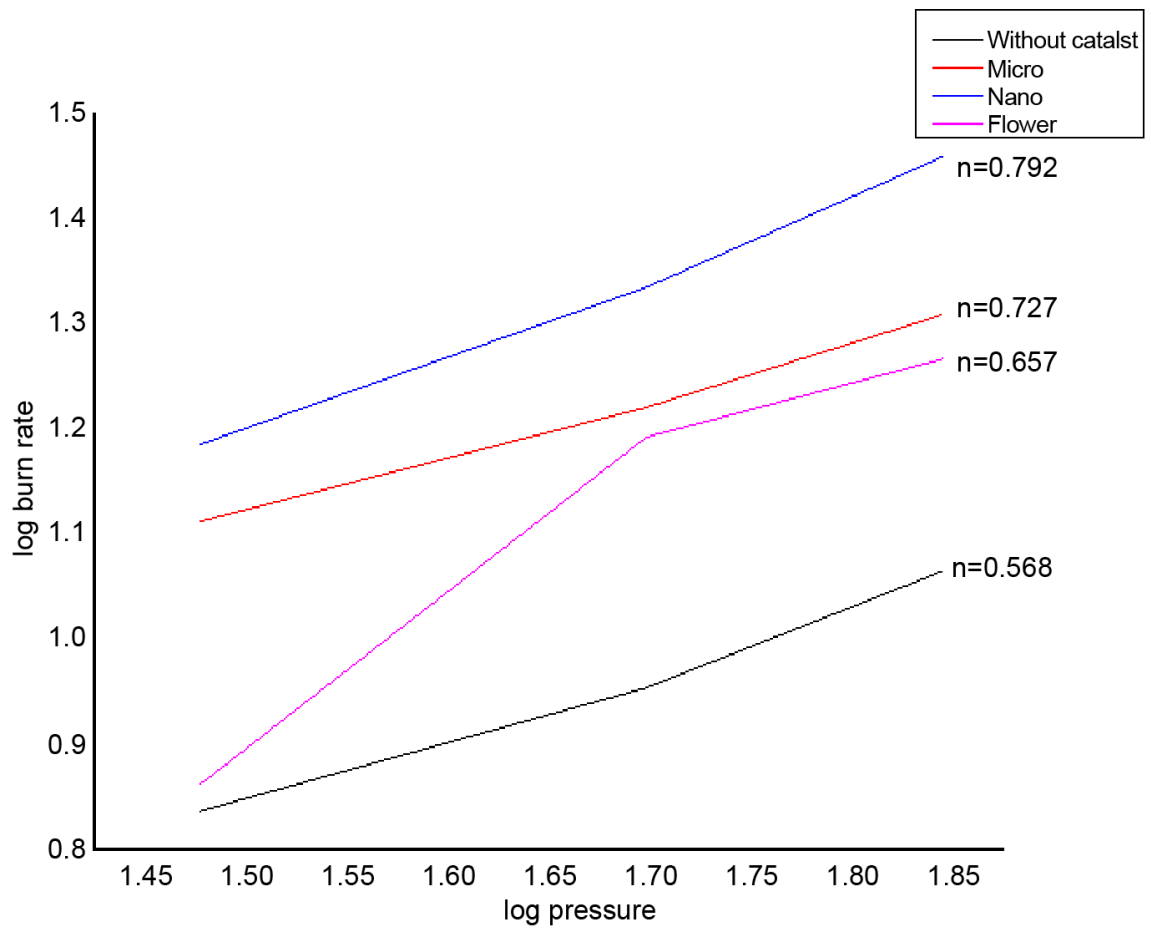

Figure 24. Log burn rate versus log pressure.

are the best burn rate enhancers when compared with a Micro, Flower shaped and a no catalyst. Table 4 gives the Log Pressure and Log Burn Rate Values for Nano, Micro, Flower, and no catalyst propellant mixtures. 
Table 4. Log pressure and $\log$ burn rate values.

\begin{tabular}{ccccccccc}
\hline $\begin{array}{c}\text { Pressure } \\
(\mathrm{Bar})\end{array}$ & \multicolumn{2}{c}{$\begin{array}{c}\text { Without Catalyst } \\
(\mathrm{Mm} / \mathrm{Sec})\end{array}$} & \multicolumn{2}{c}{$\begin{array}{c}\text { Micro } \\
(\mathrm{Mm} / \mathrm{Sec})\end{array}$} & \multicolumn{2}{c}{$\begin{array}{c}\text { Nano } \\
(\mathrm{Mm} / \mathrm{Sec})\end{array}$} & \multicolumn{2}{c}{$\begin{array}{c}\text { Flower Shaped } \\
(\mathrm{Mm} / \mathrm{Sec})\end{array}$} \\
\hline & Pressure & Fuse & Pressure & Fuse & Pressure & Fuse & Pressure & Fuse \\
\hline 30 & 5.62 & 6.9 & - & 12.98 & 15.378 & 13.157 & 8.329 & 7.299 \\
50 & 9.746 & 9.02 & - & 16.66 & 21.66 & - & 11.699 & 15.625 \\
70 & 12.326 & 11.66 & 20.408 & - & 28.776 & - & 16.827 & 18.518 \\
\hline
\end{tabular}

\section{Conclusions}

AP-based composite propellants prepared with fine AP and with higher AP contents are required to obtain a high burning rate. The dependence of burning rate and spatial distribution of heat release on various factors (including chamber pressure, AP particle size, and gas-phase reaction rate) were studied in depth. Pure, and crystalline The catalytic activities of Nano-scale catalysts are generally better than their micron-sized counterpart procured from VSSC. Nano-scale catalysts were found to be dispersed well in the propellant grain, using conventional mixing process.

Nano sized Iron Oxide catalyst has the best efficiency compared to micro, flower and no catalyst. From the graph it can be inferred that the Nanosized catalysts delivers the highest burn rate. The best substitute for Nano structured Iron Oxide catalyst are found to be the Micro structured Iron Oxide catalyst which has the second best burn rate capacity. It can also be observed, from the graph, that the burn rate is the lowest for the propellant in the absence of a catalyst. Burn rate is increased with the help of catalysts. Nano-catalysts prepared in this research program are promising as high-performing ballistic modifiers in AP-based composite propellants.

\section{References}

[1] AP Composite Basics. http://www.rimworld.com/nassarocketry

[2] Richard Nakka's Experimental Rocketry. http://www.nakka-rocketry.net/

[3] Sutton, G.P. (2000) Rocket Propulsion Elements. 7th Edition, John Wiley \& Sons, Inc., New York.

[4] Kuo, K.K. (1982) Survey of Rocket Propellants and Their Combustion Characteristics. In: Fundamentals of Solid-Propellant Combustion, Progress in Astronautics and Aeronautics, American Institute of Aeronautics and Astronautics, Reston, 1-52. https://doi.org/10.2514/5.9781600865671.0001.0052

[5] Davenas, A. (1996) Solid Rocket Motor Design, Tactical Missile Propulsion. In: Jensen, G.E. and Netzer, D.W., Eds., Progress in Astronautics and Aeronautics, Vol. 170, AIAA, Reston.

[6] Kubota, N. (1984) Combustion Characteristics of Rocket Propellants. In: Kuo, K.K. and Summerfield, M., Eds., Fundamentals of Solid-Propellant Combustion, Progress in Astronautics and Aeronautics, Vol. 90, American Institute of Aeronautics and Astronautics Inc., New York.

[7] Lu, K.-T., Yang, T.-M., Li, J.-S. and Yeh, T.-F. (2012) Study on the Burning Charac- 
teristics of AP/Al/HTPB Composite Solid Propellant Containing Nano-Sized Ferric Oxide Powder. Combustion Science \& Technology, 184, 2100-2116.

https://doi.org/10.1080/00102202.2012.703271

[8] Kohga, M. (2006) Burning Characteristics of AP/HTPB Composite Propellants Prepared with Fine Porous or Fine Hollow Ammonium Perchlorate. Propellants, Explosives, Pyrotechnics, 31, 50-55. https://doi.org/10.1002/prep.200600007

[9] Aziz, A., Mamat, R., Wan Ali, W.K. and Mohd Perang, M.R. (2015) Review on Typical Ingredients for Ammonium Perchlorate Based Solid Propellant. Applied Mechanics and Materials, 773-774, 470-475. https://doi.org/10.4028/www.scientific.net/AMM.773-774.470

[10] Styborski, J.A. (2014) Effects of Aluminum and Iron Nanoparticle Additives on Composite AP/HTPB Solid Propellant Regression Rate. Rensselaer Polytechnic Institute, New York.

[11] Zou, M., Jiang, X.H., Lu, L.D. and Wang, X. (2012) A Mechanism on Thermal Decomposition of Ammonium Perchloratecatalyzed by Cobalt Oxalate. Journal of Hazardous Materials, 225-226, 124-130.

https://doi.org/10.1016/j.jhazmat.2012.05.010

[12] Joshi, S.S., Patil, P.R. and Krishnamurthy, V.N. (2008) Thermal Decomposition of Ammonium Perchlorate in the Presence of Nanosized Ferric Oxide. Defence Science Journal, 58, 721-727. https://doi.org/10.14429/dsj.58.1699

[13] Han, A.J., Liao, J.J., Ye, M.Q., Li, Y. and Peng, X.H. (2011) Preparation of Nano- $\mathrm{MnFe}_{2} \mathrm{O}_{4}$ and Its Catalytic Performance of Thermal Decomposition of Ammonium Perchlorate, Product Engineering and Chemical Technology. Chinese Journal of Chemical Engineering, 19, 1047-1051. https://doi.org/10.1016/S1004-9541(11)60090-6

[14] Cai, W.D., Thakre, P. and Yang, V. (2008) A Model of AP/HTPB Composite Propellant Combustion in Rocket-Motor Environments. Combustion Science and Technology, 180, 2143-2169. https://doi.org/10.1080/00102200802414915

[15] Eisenreich, N., Kugler, H.P. and Sinn, F. (1987) An Optical System for Measuring Burning Rates of Solid Propellants. Propellants, Explosives, Pyrotechnics, 12, 78-80. https://doi.org/10.1002/prep.19870120304

[16] Kohga, M. and Hagihara, Y. (1998) Burning Behavior of Composite Propellant Containing Fine Porous Ammonium Perchlorate. Propellants, Explosives, Pyrotechnics, 23, 182-187.

https://doi.org/10.1002/(SICI)1521-4087(199808)23:4<182::AID-PREP182>3.0.CO; $\underline{2-\mathrm{A}}$ 